\title{
Determinación y caracterización de situaciones de temporal marino e inundación costera por rebase del oleaje en San Andrés, NE de Tenerife (1984-2014)
}

\author{
Determining and distinguishing sea storms and coastal flood wave \\ overtopping in San Andrés, NE of Tenerife (1984-2014)
}

\author{
José Ángel Rodríguez-Báez ${ }^{1}$ \\ Amalia Yanes Luque ${ }^{2}$ \\ Pedro Dorta Antequera ${ }^{3}$
}

\section{Resumen}

Los objetivos de este trabajo son la determinación y caracterización de situaciones de temporal marino e inundación costera por rebase del oleaje en San Andrés (NE de Tenerife) entre 1984 y 2014. Para ello, se realiza un análisis estadístico de los parámetros de oleaje (Hs, Hmax, Tp, L y Dirección) y dirección y velocidad del viento a partir de datos de modelos numéricos de generación y propagación de uno y otro (SIMAR, Puertos del Estado). Se identifican 56 temporales tras el establecimiento de un umbral de riesgo de 2,6 metros de altura de ola significante (Hs) mediante la aplicación del percentil 99. A continuación, se examinan en detalle dos de ellos por lo representativo del comportamiento de las olas y situación atmosférica que los origina. Aunque el $57,1 \%$ de los temporales es invernal, se analizan dos inundaciones costeras acontecidas en verano, en relación con la marea viva astronómica. Se trabaja también con la prensa, pues permite constatar la incidencia social y económica de los fenómenos en estudio y reconocer inundaciones que no registran los modelos numéricos.

Palabras clave: temporal marino; inundación costera por rebase del oleaje; umbral de riesgo; San Andrés; Tenerife.

\begin{abstract}
The purpose of this study is to determine and distinguish sea storms and coastal flood wave overtopping events in San Andrés (NE, Tenerife) between 1984 and 2014. Therefore, a detailed statistical analysis of wave, direction and wind speed is carried out using numerical model data on the propagation of waves and wind (SIMAR, Puertos del Estado). 56 sea storms are identified by establishing a risk threshold of 2.6 meters as being a significant wave height (Hs). In turn, a detailed examination of two significant storms is conducted to study the behaviour of the waves and the atmospheric conditions that cause them. While $57.1 \%$ of sea storms occur in winter, two coastal floods that happened in summer are analysed in relation to the role of the astronomical spring tide. Finally, the press is used to verify the social and economic impact of the phenomena under analysis, the damage they cause, and to identify the floods that do not record numerical models.
\end{abstract}

Keywords: sea storm; coastal flood wave overtopping; risk threshold; San Andrés; Tenerife.

\footnotetext{
1 Cátedra de Reducción del Riesgo de Desastre. Ciudades Resilientes. Universidad de La Laguna, España. jrodbaez@ull.es

2 Departamento de Geografía e Historia. Universidad de La Laguna, España. ayanes@ull.es

3 Cátedra de Reducción del Riesgo de Desastre. Ciudades Resilientes. Universidad de La Laguna, España.pdorta@ull.es
} 


\section{Introducción}

Las inundaciones costeras asociadas a temporales marinos y/o rebase del oleaje han suscitado un interés creciente en la comunidad científica a partir, sobre todo, de las previsiones del Grupo Intergubernamental de Expertos sobre el Cambio Climático [IPCC] de un ascenso del nivel medio del mar a escala global para finales del siglo XXI y de los fenómenos meteorológicos extremos (Olcina, 2008). Si ya en su primer informe (1990) el [IPCC] anuncia que dicho ascenso puede ser de 0,15 a 0,95 metros, en el cuarto (2007) el escenario contemplado lo sitúa entre 0,25 y 0,60 metros por encima del actual (Benavente, del Río y Gracia, 2009), mientras que en el último (2013) señala que, en el 70\% de las costas del planeta, el mar subirá hasta en un $20 \%$ más sobre el nivel medio proyectado. A esta perspectiva de futuro se añade la intensificación de los procesos de litoralización, considerando que, aproximadamente, el $60 \%$ de la población mundial vive a menos de $100 \mathrm{~km}$ de la costa, cifra que puede ser del $75 \%$ en 2020, según previsiones de la ONU (Benavente et al, 2009).

La incertidumbre generada por el cambio climático y la cada vez mayor presencia de población en el medio costero hacen necesaria la adopción de nuevas formas de gestión, reducción y mitigación de los riesgos asociados al mar (Olcina, 2008; [IPCC], 2013). Lo apunta la entrada en vigor de la Directiva 2007/60/CE del Parlamento y Consejo Europeo de 23/10/2007, cuando reconoce que las inundaciones son una amenaza social, cultural, económica y medioambiental. De ahí que tenga como objetivos la identificación y cartografía de las cuencas hidrográficas y regiones costeras más proclives a las mismas, así como el diseño de una política de planificación de usos del suelo acorde con ese riesgo.

Por lo que respecta a España, la importancia concedida al conocimiento de las inundaciones y erosión costeras ha ido en ascenso. Ello se puede deber, en parte, a las pérdidas económicas que ocasionan, unos 4.000 millones de euros estimados entre 1986 y 2016 (Seisdedos et al., 2013), y a las víctimas mortales que causan, 511 por temporales marinos entre 1990 y 2000 (Seisdedos et al, 2013). En esta línea cabe destacar, de un lado, la elaboración por la Dirección General de Costas del "Atlas de Cota de Inundación Peninsular Español" (1999) y los estudios de la Oficina Española de Cambio Climático orientados a evaluar los impactos de dicho cambio en la costa, así como el establecimiento de políticas y estrategias de actuación para prevenir y mitigar los posibles efectos futuros en el frente litoral (Ministerio de Agricultura y Pesca, Alimentación y Medio Ambiente, 2004; Medina y Méndez, 2006). Con todo, aún son escasos los trabajos relacionados con la futura evolución del comportamiento del nivel medio del mar en áreas concretas, más allá de algunas aproximaciones parciales a los peligros vinculados a la dinámica litoral en Cataluña y Andalucía (Seisdedos et al, 2013; Fraile, Sánchez, Fernández, Pita y López, 2014). Y, de otro lado, la transposición de la citada Directiva Europea de Inundaciones al ordenamiento jurídico español mediante el Real Decreto 903/2010, de 9 de julio. Este regula los procedimientos y plazos para valorar en todo el territorio español el riesgo de inundación fluvial y costera con la evaluación preliminar del riesgo de inundación (en adelante EPRI); a ello sigue la elaboración de mapas de peligrosidad y riesgo (en adelante MPYR), definiendo las Áreas de Riesgo Potencial Significativo de Inundación (ARPSI); y, por último, la realización de los planes de gestión de los riesgos de inundación. Este Real Decreto se complementa, paralelamente, con el del 9/2008, de 11 de enero, por el que se crea el Sistema Nacional de Cartografía de Zonas Inundables, que incorpora la información recogida en los mapas de peligrosidad y de riesgo de inundación (RDL 903/2010, de 9 de julio).

Canarias, por su parte, ha conocido un aumento de la exposición y vulnerabilidad a los riesgos costeros dada la rápida ocupación de su litoral, al tratarse de un ámbito de modesta dimensión y carácter montañoso que ha implantado, a partir de 1960, un modelo económico turístico-inmobiliario (Pérez-Chacón, Hernández Calvento y Yanes, 2007). Desde entonces, la frecuencia e incidencia espacial y temporal de tales riesgos es cada vez mayor, ante el notable trasvase de población de las medianías ${ }^{4}$ hacia la costa y el crecimiento del número de turistas que visitan cada año el archipiélago (69.000 en 1960 y más de 13 millones en 2015).

A pesar de que los Consejos Insulares de Aguas de cada isla han finalizado los trabajos relativos a las EPRIs y MPYRS ${ }^{5}$, procediéndose a su aprobación, las inundaciones son una amenaza poco conocida

4 Banda bioclimática entre 400 y 1000 metros de altura que, por su mayor humedad, concentraba la actividad agraria y el poblamiento tradicional.

5 Sigue en proceso de desarrollo la elaboración de los planes de gestión de los riesgos de inundación, que debieron publicarse y aprobarse antes del 22/12/2015 tal y como establece la Directiva de Inundaciones (RDL 903/2010, de 9 de julio), (Consejo Insular de Aguas de El Hierro, s.f.) 
en comparación con otros riesgos. Muestra de ello es la limitada información sobre temporales marinos, pues, aunque se cuenta con estudios puntuales sobre el clima marítimo de Canarias y eventos extremos en el mar (Afonso, 2007, 2011), los análisis realizados se centran sobre todo en Tenerife (Yanes, Marzol y Romero, 2007; Yanes y Marzol, 2009). En este contexto, el probable incremento futuro de las tormentas en la costa norte de Canarias y el giro horario de las direcciones del oleaje en la sur por efecto del cambio climático plantean otra incertidumbre acerca de nuevos procesos desencadenantes de inundaciones costeras (Medina y Méndez, 2006). A tenor de estas consideraciones, en el presente trabajo se hace hincapié en la identificación y análisis, por un lado, de episodios de temporal marino a partir del establecimiento de un umbral de riesgo para su individualización frente al comportamiento habitual del oleaje; y, por otro, de invasiones marinas por efecto de rebase de las olas.

\subsection{El área de estudio y su contexto geográfico}

El área de estudio se localiza en el extremo septentrional de la vertiente este-sureste de Tenerife (Canarias); concretamente, en el noreste de su capital y al sur del Macizo de Anaga. Con una extensión de $20,9 \mathrm{~km}^{2}$ está constituido por tres pequeñas entidades de población - Ladera de San Andrés, El Suculum y San Andrés -, que se extiende entre la Dársena Pesquera de Santa Cruz de Tenerife (SO) y la playa de Las Teresitas (NE) mediando entre ambas la Autovía de San Andrés (TF-11). Los restantes límites son el mar por el sur y los antiguos acantilados del Macizo de Anaga por el norte (fig. 1). En este ámbito, el trabajo se centra en la Avenida Marítima de San Andrés y su entorno inmediato, la primera línea de costa hasta donde el oleaje se adentra en situaciones de cierta energía. Se trata de una franja de $0,07 \mathrm{~km}^{2}$ con 1.619 habitantes (2014) alojados sobre todo en el litoral, siendo su densidad de 23.129 hab/km². Este enclave forma parte de una de las treinta y siete zonas inundables identificadas en Tenerife por fenómenos litorales (Consejo Insular de Aguas de Tenerife, 2014), que ha sido objeto de examen desde el campo de la ingeniería de cara a solventar sus graves inundaciones (Mora et al., 2013; Cordobés, 2014).

Figura 1. Área de estudio
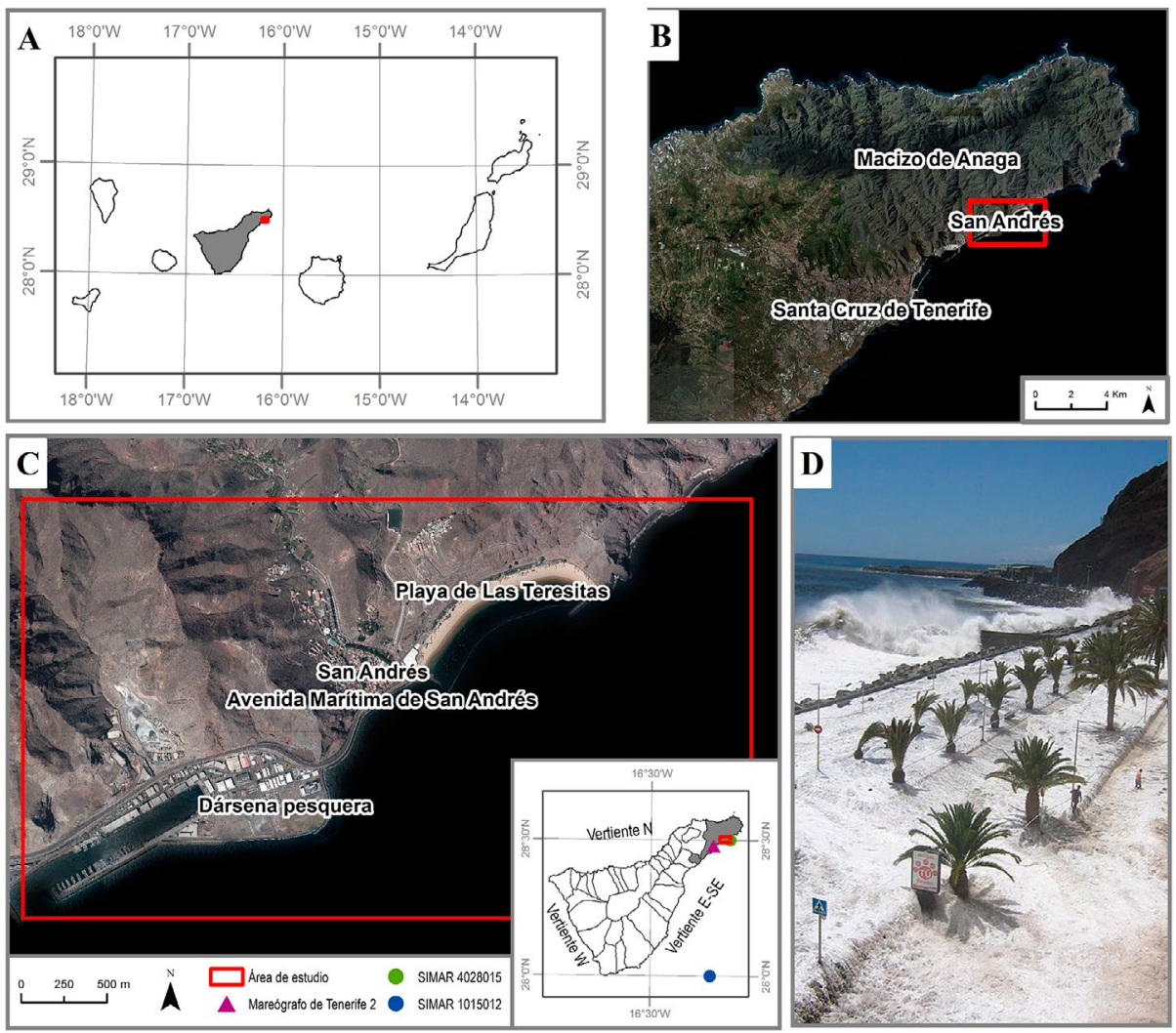

A) Islas Canarias. B) Extremo noreste de la isla de Tenerife. C) Localización de San Andrés y de los modelos de oleaje SIMAR y del Mareógrafo Tenerife 2. D) Inundación costera de la Avenida Marítima (29-31/VIII/2011).

Fuente: Cartográfica de Canarias S.A. [GRAFCAN] y Puertos del Estado. Elaboración propia. Foto: Diario de Avisos (2012). 
Aunque en sus inicios San Andrés basa su economía en la pesca y agricultura, la expansión de Santa Cruz de Tenerife favorece su conversión en un núcleo terciarizado a partir de la década de 1960. Ante la escasez de espacios llanos, en su mayoría vinculados a desembocaduras de barrancos, y la proliferación de pronunciados acantilados, esa expansión se efectúa mediante terrenos ganados al mar (Pérez-Chacón et al., 2007). La artificialización del frente costero se materializa en la prolongación del dominio edificado de Santa Cruz de Tenerife hacia el noreste, en la realización de la Autovía de San Andrés (1975) y de su Avenida Marítima y en la transformación de la playa de Las Teresitas (1973). En el ámbito que se considera, son de especial relevancia, por un lado, la construcción de una escollera en la parte delantera de dicha Avenida y su disposición sobreelevada con respecto al pequeño cordón de cantos y arenas basálticas que era la playa original de San Andrés, de modo que el caserío se encuentra hoy por debajo del nivel del mar (Cordobés, 2014). Y, por otro lado, la ampliación de la también modesta playa de Las Teresitas en 80 metros adicionales, gracias a arenas calcáreas procedentes del Sáhara. Todo ello debido a lo reducido de los aportes locales, que hace necesaria la edificación de dos espigones laterales y un rompeolas de 1 kilómetro de longitud a unos 500 metros de la orilla, para preservar el nuevo sustrato y minimizar la acción del oleaje en la zona de baño (Jordán, Boix, De la Fuente y Sanfeliu, 1996). Estas actuaciones, que alteran de forma notable la configuración costera inicial, hacen del área de estudio uno de los lugares de ocio más representativos del municipio de Santa Cruz de Tenerife. Muestra de ello es que cuenta con más de 20 bares y restaurantes en primera línea de costa y una alta intensidad de tráfico, cifrada en una media diaria de 14.181 vehículos en 2014 (Cabildo Insular de Tenerife, 2015).

La localización y evolución señaladas determinan que San Andrés sea un espacio de riesgo. Su afectación por peligros de origen natural diverso, con notables secuelas sobre la población y sus actividades, es un rasgo característico de esta entidad. A pesar de la orientación de la costa y del relativo abrigo que propicia al oleaje la península de Anaga, San Andrés es conocido por las inundaciones debidas a temporales marinos y/o mareas vivas astronómicas. Estas inundaciones constituyen un fenómeno de incidencia creciente en litorales antropizados (Olcina, 2008, 2011; Benavente et al., 2009), lo que en este tramo litoral de Tenerife supone valorar los cambios que experimenta la dirección del oleaje en función de la configuración costera. Además, también es de destacar la existencia de una trama urbana con calles perpendiculares a la línea de costa con la posibilidad de que, en situaciones de fuerte oleaje, las olas se adentren con facilidad en el caserío. A estas inundaciones se suman las causadas, en los últimos años, por el desbordamiento de los barrancos del Cercado y Las Huertas tras lluvias de carácter torrencial (31/ III/2002 y 19/X/2014) que se han repetido a lo largo de la historia. Lo atestigua el Castillo de San Andrés, arruinado por varios temporales acontecidos durante el siglo XIX, siendo el de mayor consideración el de 1826, que se ha catalogado como el peor evento climático ocurrido en Canarias (Bethencourt \& Dorta, 2010; Sabaté, 2012).

El diseño y desarrollo de toda actuación en el frente litoral exige el conocimiento y cálculo de la cota de inundación costera (Tros de Ilarduya, 2005, 2012), máxime cuando la urbanización se prolongue hasta la zona de rompientes y/o conlleve un avance efectivo de aquel a expensas de terrenos ganados al mar. La magnitud de la inundación de San Andrés del 29-31/VIII/2011 lo demuestra. En la prensa escrita se comprueba la existencia de sucesos similares en el pasado, de modo que las invasiones del mar, ya sea por temporal o rebase del oleaje, no son fenómenos novedosos en esta localidad. Su constatación hace que el objetivo central de este estudio sea el establecimiento de un umbral para identificar episodios de temporal marino, tras caracterizar el régimen medio anual y estacional del oleaje en San Andrés. El análisis de tales episodios, así como de las inundaciones no propiciadas por temporales, constituye otro de los objetivos del trabajo, con especial hincapié en la determinación del comportamiento del oleaje y viento y de las situaciones atmosféricas que los desencadenan.

\section{Metodología}

Las fuentes consultadas a tal fin son el Banco de Datos Oceanográfico de Puertos del Estado, la Agencia Estatal de Meteorología [AEMET], la prensa regional y la sección de Protección Civil del Ayuntamiento de Santa Cruz de Tenerife. El primero proporciona datos de oleaje direccional correspondientes a los modelos numéricos de generación y propagación de olas SIMAR $4028015\left(28,50^{\circ} \mathrm{N}, 16,17^{\circ} \mathrm{W}\right)$ y SIMAR $1015012\left(28,00^{\circ} \mathrm{N}, 16,25^{\circ} \mathrm{W}\right)$, para una serie temporal de treinta años (1984-2014). Estos modelos de la Red SIMAR resultan de la concatenación de los conjuntos de datos simulados SIMAR-44 y WANA, por lo que no proceden de medidas directas a partir de registros instrumentales (Puertos del Estado, 2015a). Por 
su parte, el Mareógrafo de Tenerife 2 de la Red REDMAR $\left(28,48^{\circ} \mathrm{N}, 16,24^{\circ} \mathrm{W}\right)$ aporta información diaria y horaria sobre el nivel del mar mediante datos obtenidos en tiempo real (Puertos del Estado, 2015b). De la segunda fuente proceden los boletines meteorológicos que permiten conocer las configuraciones barométricas en altura y superficie causantes de situaciones de temporal marino e inundación costera. Se consultan, además del mapa de superficie, las topografías de 300, 500 y $850 \mathrm{hPa}$. En cuanto a las noticias sobre episodios de oleaje extremo, se extraen de los diarios Canarias 7, Diario de Avisos, El Día, Jornada Deportiva, La Gaceta, La Opinión de Tenerife y La Provincia, que se consultan a través de la Biblioteca Digital de la Universidad de La Laguna. Algunas reseñas se obtienen también en buscadores de los entornos webs oficiales de dichos periódicos, pues la disponibilidad de los rotativos de la plataforma universitaria se limita al período 1996-2015. La prensa regional se completa con datos de oleaje para el período 20102015 facilitados por la Sección de Protección Civil del municipio.

La metodología empleada es de carácter cuantitativo y cualitativo, al realizarse un análisis estadístico del oleaje y viento y una apreciación del contenido de las noticias de prensa y situación sinóptica. El análisis estadístico se efectúa sobre parámetros del oleaje aportados por los modelos SIMAR a razón de ocho datos diarios, que se corresponden con las 0:00, 3:00, 6:00, 9:00, 12:00, 15:00, 18:00 y 21:00 horas. Tales parámetros son la ola significante (Hs, metros), el período pico ( $\mathrm{Tp}$, segundos), la dirección del oleaje y viento (grados) y su velocidad (metros/segundos). A partir de los dos primeros se calculan la ola máxima (Hmax, metros) y la longitud de ola (L, metros), en un caso y otro; al mismo tiempo se convierte la dirección del oleaje y viento de grados a rumbos y la velocidad de metros/segundos a kilómetros/hora.

Tabla 1. Muestra de la recopilación de datos e imágenes sobre temporales marinos e inundaciones costeras por rebase del oleaje en San Andrés, Tenerife (1984-2014)

\begin{tabular}{|c|c|c|c|c|c|c|c|c|c|}
\hline \multirow{3}{*}{ 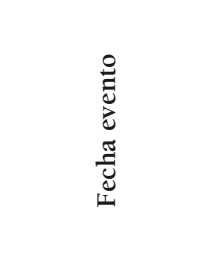 } & \multirow{3}{*}{ 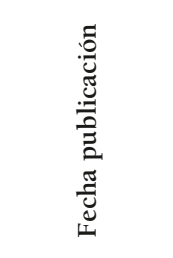 } & \multicolumn{6}{|c|}{ Prensa } & \multirow{3}{*}{ Exposición } & \multirow{3}{*}{ 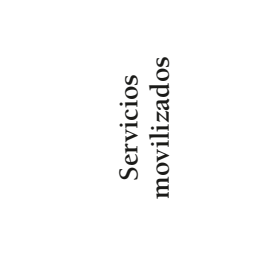 } \\
\hline & & \multicolumn{3}{|c|}{$\begin{array}{c}\text { Diario de } \\
\text { Avisos }\end{array}$} & \multicolumn{3}{|c|}{ El Día } & & \\
\hline & & 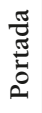 & $\stackrel{0}{\circ}$ & $\begin{array}{l}\stackrel{n}{0} \\
\stackrel{0}{0} \\
\stackrel{0}{Z}\end{array}$ & 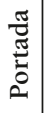 & $\stackrel{0}{\stackrel{0}{0}}$ & \begin{tabular}{l}
0 \\
$\stackrel{0}{0}$ \\
\hdashline \\
$\dot{Z}$
\end{tabular} & & \\
\hline \multirow{2}{*}{ 01-02/ VI/ 2014} & 02/NI/ 2014 & 1 & 3 & 4 & 1 & 3 & 3 & \multirow{2}{*}{$\begin{array}{c}\text { Corte al tráfico de la Avenida y retirada de } \\
\text { vehículos. Arrastre de piedras hasta cerca de casas } \\
\text { y comercios. }\end{array}$} & \multirow{2}{*}{$\begin{array}{l}\text { Policía Local, Protección } \\
\text { Civil, Urbaser. }\end{array}$} \\
\hline & 03/VI/ 2014 & & & & 0 & 2 & $2 *$ & & \\
\hline 05/II/ 2012 & 06/II/ 2012 & 1 & 2 & 2 & 1 & 3 & 2 & $\begin{array}{l}\text { Cierre del acceso al barrio tras arrastre de piedras } \\
\text { y tierra desde la escollera en construcción. }\end{array}$ & $\begin{array}{l}\text { Policía Local, Protección } \\
\text { Civil, Urbaser. }\end{array}$ \\
\hline \multirow[b]{2}{*}{ 28-29/ VIII/ 2011} & 30/VIII/ 2011 & 1 & 3 & 11 & 1 & 3 & 9 & \multirow{2}{*}{$\begin{array}{c}\text { Llegada de las olas hasta playa de Las Teresitas y a } \\
\text { más de } 100 \text { m hacia el interior del barrio. Corte al } \\
\text { tráfico de la vía de San Andrés. } 5 \text { casas inundadas, } \\
15 \text { vehículos inservibles, } 3 \text { agujeros abiertos por } \\
\text { el oleaje en entrada del barrio y graves daños en } \\
\text { sebadales trasplantados. }\end{array}$} & \multirow[b]{2}{*}{$\begin{array}{l}\text { Policía Local, Protección } \\
\text { Civil, Urbaser, Emmasa, } \\
\text { Unelco, Bomberos, } \\
\text { Dragados, Serv. Sociales }\end{array}$} \\
\hline & 31/VIII/ 2011 & 1 & 3 & 10 & 1 & 3 & $5 *$ & & \\
\hline 08/I/ 1999 & 09/I/ 1999 & 0 & 2 & 1 & 0 & 2 & $4 *$ & $\begin{array}{c}\text { Cierre al tráfico del acceso al barrio por olas de } \\
\text { más de } 3 \text { m de altura y retirada de pequeñas } \\
\text { embarcaciones. }\end{array}$ & \\
\hline 27/VIII/1996 & 28/VIII/ 1996 & 1 & 3 & 2 & 1 & 3 & $4 *$ & $\begin{array}{c}\text { Cierre acceso a playa de Las Teresitas. Inundación } \\
\text { de varias viviendas de } 1^{\text {aa }} \text { línea de costa. Arrastre } \\
\text { de grandes piedras en la Avenida. }\end{array}$ & $\begin{array}{l}\text { Policía Local, Emmasa, } \\
\text { Bomberos. }\end{array}$ \\
\hline
\end{tabular}

Portada: (0) No hay información San Andrés; (1) Hay información San Andrés.

Foto: (0) No hay; (1) En portada; (2) En página interior; (3) En portada y página interior.

$\mathrm{N}^{\text {o }}$ fotos: cantidad de fotos referidas a San Andrés.

(*)Sólo se contabilizan las imágenes que ilustran los daños materiales y el mal estado del mar.

Fuente: Prensa consultada y Protección Civil de Santa Cruz de Tenerife. Elaboración propia.

Para el tratamiento de las variables señaladas, se elabora una base de datos a partir del modelo SIMAR 4028015. Sin embargo, la identificación de irregularidades en la serie temporal exige completar las lagunas existentes cuando el vacío de información es muy amplio (31/XII/1999 a 21/II/2005). Se recurre entonces a la extrapolación de datos del modelo SIMAR 1015012 tras la correlación de Pearson diaria 
de la Hs, el Tp y velocidad del viento, cuyo resultado es de $0,70,0,46$ y 0,70 , respectivamente. Al ser el valor de la correlación del Tp algo bajo $(0,46)$, su análisis, y por consiguiente el de la L, puede sufrir ligeras variaciones en las medias anuales y estacionales, aunque se estima que no repercuten de manera relevante en los resultados finales del estudio. Las escalas temporales usadas en el análisis de los registros son diversas. Así, la caracterización del régimen habitual del oleaje y sus variaciones según época del año tiene lugar a nivel anual y estacional. Se procede a partir de la media de los valores de las 9:00 y 18:00 horas, pues son los que mejor reflejan el comportamiento de las olas al recoger las diferencias que puede introducir la incidencia de las brisas (Pardo, 1991). En contraposición a ello, la determinación de un umbral para detectar condiciones de tormenta precisa una escala de análisis diaria y horaria. Estas se aplican, asimismo, al estudio de los episodios de temporal marino individualizados.

La información periodística se trabaja mediante una base de datos específica, partiendo de la importancia que se atribuye a la prensa como medio que documenta, relata y analiza fenómenos naturales adversos, en función de sus secuelas ambientales, sociales y económicas (Duce, 1995; Máyer 1999; Yanes y Marzol, 2009). Los campos que la integran son fecha real, u orientativa en su caso, del temporal marino o inundación costera; origen; fecha de publicación y repercusión socioeconómica del suceso, según se tengan o no imágenes de lo acontecido en portada y/o en páginas interiores y su cantidad; elementos expuestos; daños personales y actuación de medios públicos. Así se consignan, a modo de ejemplo, en la tabla 1, a partir de la información extraída de los periódicos Diario de Avisos y El Día, que se complementa con datos proporcionados por Protección Civil de Santa Cruz de Tenerife. Por último, se examinan la disposición de los centros de presión y la determinación y clasificación del tipo de tiempo durante las situaciones de temporal marino e inundación costera.

\section{Resultados}

\subsection{Régimen medio anual y estacional del oleaje}

El régimen habitual del oleaje en San Andrés se caracteriza por la importancia de un sea del NNE $(43,8 \%)$ ligado a vientos de igual rumbo y velocidad media anual de $18,3 \mathrm{~km} / \mathrm{h}$. Su naturaleza moderada se relaciona con una Hs de 1,1 metros de altura, Tp de 8,6 segundos y L de 129,2 metros. Abunda en esta línea el hecho de que casi la mitad de los días del año la Hs alcanza, por término medio, hasta 1 metro de altura y la Hmax se sitúa en el 45,4\% entre 1-2 metros, coincidiendo con el predominio de períodos cortos (6-10 segundos 53,2\%) y pequeña longitud (45-100 metros 41,4\%). Asimismo, la intensidad de los flujos del NNE $(32,5 \%)$ es de $10-20(44,2 \%)$ a $20-30 \mathrm{~km} / \mathrm{h}$ (38\%) (tabla 2 y gráfico 1 ). Estos valores son muy similares a los reconocidos en Tenerife entre 1985-2003 (Yanes y Marzol, 2009), donde prevalece un sea del NNE-NE, con una Hs de 1,4 metros de altura, 9,4 segundos de Tp y 162,6 metros de L, en respuesta a vientos alisios de 18 a $22 \mathrm{~km} / \mathrm{h}$. No obstante, la orientación y exposición de la costa modifican estos registros, según se trate de la norte, oeste y este-sureste de la isla. A pesar de que el área de estudio se emplaza en esta última, su oleaje difiere del que le es propio, si se tiene en cuenta que en esa costa la Hs, Tp y L se cifran en 0,7 metros de altura, 7,1 segundos y 97,1 metros, respectivamente.

Tabla 2. Valores medios anuales y estacionales de los parámetros de oleaje y viento de Tenerife (1985-2003), San Andrés (1984-2014) y vertiente este-sureste de la isla (1985-2003)

\begin{tabular}{|c|c|c|c|c|c|c|c|c|c|c|c|}
\hline \multirow{2}{*}{ Parámetros } & \multicolumn{4}{|c|}{ Tenerife } & \multicolumn{5}{c|}{ San Andrés } & \multicolumn{3}{c|}{ Vertiente E-SE } \\
\cline { 2 - 14 } & Año & Inv & Ver & Año & Inv & Prim & Ver & Oto & Año & Inv & Ver \\
\hline Hs (m) & 1,4 & 1,7 & 1,1 & 1,1 & 1,2 & 1,1 & 1 & 1 & 0,7 & 0,8 & 0,8 \\
\hline Hmax (m) & 2,2 & 2,7 & 1,8 & 1,9 & 2,1 & 1,9 & 1,8 & 1,7 & 1,2 & 1,3 & 1,3 \\
\hline Tp (s) & 9,4 & 10,5 & 7,2 & 8,6 & 9,8 & 8,7 & 7 & 8,8 & 7,1 & 7 & 6,6 \\
\hline L (m) & 162,6 & 204 & 118,2 & 129,2 & 170,9 & 130,3 & 79,4 & 136,9 & 97,1 & 101 & 77,6 \\
\hline VelV $(\mathbf{k m} / \mathbf{h})$ & 22,1 & 22,4 & 24,5 & 18,3 & 17,8 & 18,3 & 20,8 & 16,3 & 21,9 & 22 & 25,6 \\
\hline DirOlj & NNE & NNW & NNE & NNE & NNE & NNE & NNE & NNE & NE & NE & NE \\
\hline DirVto & NE & NE & NNE & NNE & NE & NNE & NNE & NNE & NE & NE & NNE \\
\hline
\end{tabular}

Fuente: Puertos del Estado y adaptación de Yanes y Marzol (2009). Elaboración propia. 
El comportamiento de las olas en San Andrés presenta, también, rasgos estacionales específicos. Estando el invierno en Tenerife dominado por un swell con una Hs de 1,7 metros, 10,5 segundos de Tp y 204 metros de L, en San Andrés se contabilizan en esa época del año 1,2 metros de altura de Hs, 9,8 segundos de Tp y 170,9 metros de L. Así y todo, la hegemonía del swell del NNE hace que las Hs (49,3\%) y Hmax (37,5\%) tengan de 1 a 2 -incluso más de $3(1 \%)$ - metros de altura de Hs, el Tp ronde entre 10 y 14 segundos $(34,9 \%$ ) y la L supere los 300 metros (13,9\%). Por su parte, el viento es del NE $(22,3 \%)$ con una intensidad de 10 a $20 \mathrm{~km} / \mathrm{h}$ durante el $46,9 \%$ de la estación; solo de modo puntual se rebasan los 40 $\mathrm{km} / \mathrm{h}(0,6 \%)$. En verano, se impone un sea del NNE $(70,1 \%)$ con unas Hs y Hmax de 1 y 1,8 metros en un caso y otro, mientras el Tp oscila entre 6 y 10 segundos $(72,1 \%)$ y la L entre 45 y 100 metros $(63,4 \%)$.

Gráfico 1. Distribución media anual (\%) de los parámetros de oleaje y viento en San Andrés, Tenerife (1984-2014)

A

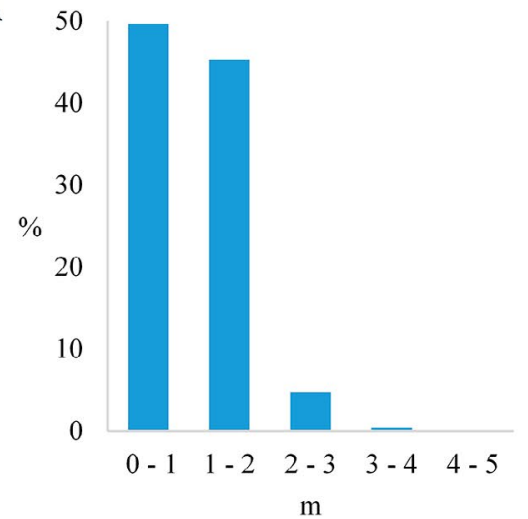

C

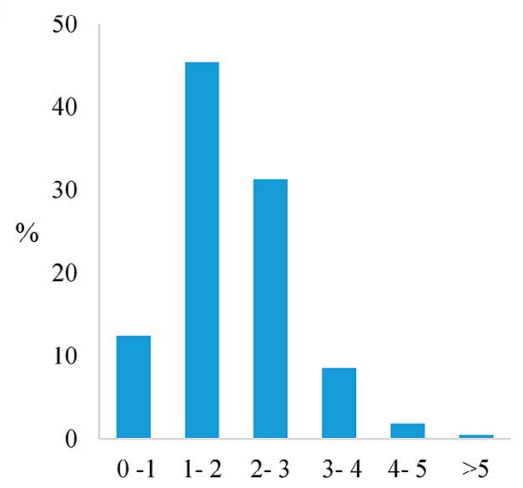

$\mathrm{m}$

$\mathbf{E}$

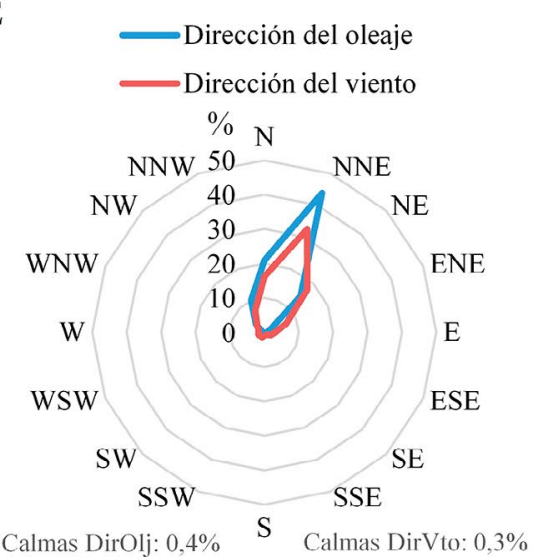

B

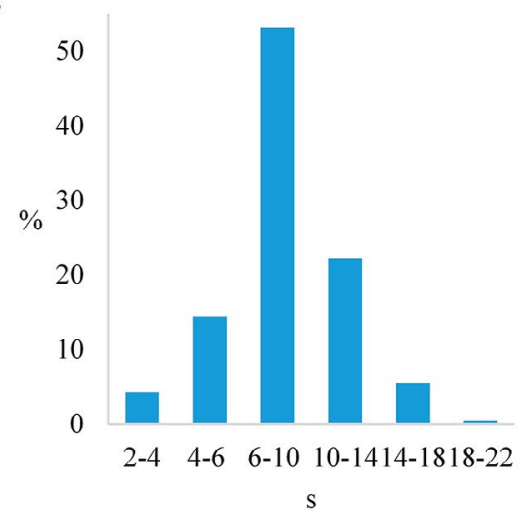

D

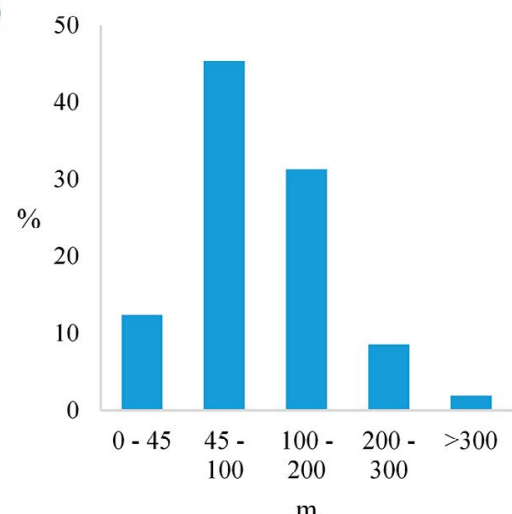

$\mathbf{F}$

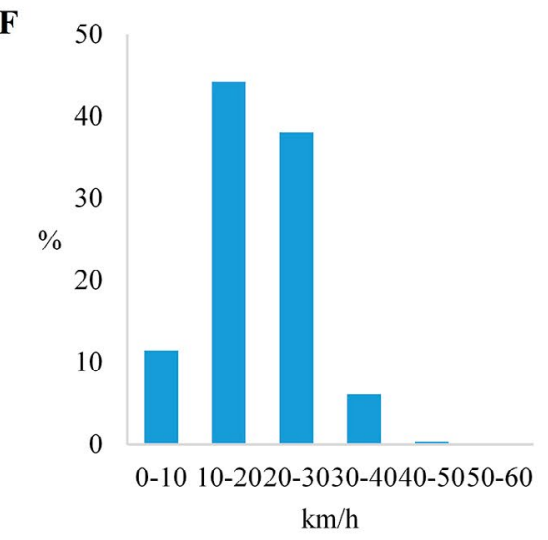

A) Altura de Hs; B) Tp; C) Altura de Hmax; D) L; E) Dirección de oleaje y viento; F) Velocidad del viento

Fuente: Puertos del Estado. Elaboración propia. 
La importancia de los vientos del NNE es notable por su frecuencia (53,9\%) y velocidad, al ser de 20 a $30 \mathrm{~km} / \mathrm{h}$ (54,3\%) dado el reforzamiento del Anticiclón de las Azores. En conjunto, estos valores se asemejan mucho a los de Tenerife, considerando que en el estío el oleaje que actúa en la isla está conformado por una Hs de 1,1 metros, 7,2 segundos de Tp y 118,2 metros de L. En los equinoccios se producen algunos pequeños cambios con respecto a lo señalado. Lo más destacable es la transición del swell invernal a un sea que se instaura a partir de la primavera, pues las olas tienden a ser de menor período, longitud y altura. En otoño, el rasgo que singulariza el estado del mar es, quizás, la mayor constancia del sea del NNE $(38,8 \%)$ con olas inferiores a 1 metro $(58 \%)$.

Los rasgos apuntados resultan, en gran medida, de la localización de San Andrés en el extremo septentrional de la vertiente este-sureste de Tenerife. Aun participando de su oleaje habitual, San Andrés está resguardado de olas que llegan a Canarias desde latitudes más altas, como las generadas en el Atlántico Norte en relación con vientos de una intensidad infrecuente en el entorno del archipiélago. Estas conforman un oleaje desarrollado que alcanza a la abierta y expuesta costa norte de Tenerife a partir de un fetch amplio, a veces de más de $3.000 \mathrm{~km}$. La presencia y efectividad de dicho oleaje se reducen en el litoral oriental, pues al tener que contornear la península de Anaga experimenta una cierta pérdida de energía por difracción. De este modo, el oleaje de San Andrés no es tan enérgico como el que se puede registrar, sobre todo en invierno, en la costa norte de la isla, pero tampoco es tan moderado como el que caracteriza al resto de la este-sureste.

\subsection{Determinación y aplicación de un umbral de riesgo}

En este trabajo se entiende por temporal marino toda aquella situación de oleaje de energía superior a la habitual provocada por fenómenos meteorológicos adversos, causen o no daños en la costa (Pardo, 1991; Benavente et al., 2009; Yanes y Marzol, 2009). Tal situación puede coincidir, además, con la marea meteorológica y/o combinarse con fases de pleamares vivas astronómicas, aunque una u otra de esas circunstancias no ha de concurrir necesariamente en la generación de tormentas en el mar.

El reconocimiento de episodios de temporal marino se realiza en el área de estudio por medio del análisis estadístico del oleaje y viento a nivel diario y horario. A fin de identificar situaciones en las que el comportamiento del oleaje difiera con claridad del régimen medio anual, se ensaya con los percentiles 95 y 99 de los promedios diarios de la altura de la Hs (Yanes et al., 2007; Rangel \& Anfuso, 2013; Lionello, s.f), que arrojan un valor de 2 y 2,6 metros, respectivamente. En función de estos resultados, se opta por el registro del percentil 99 , puesto que refleja el $1 \%$ de los eventos más extremos de la serie estadística y se estima más representativo de los valores extremos.

El empleo de un umbral de 2,6 metros de altura de Hs posibilita individualizar 108 fechas, que, agrupadas por días consecutivos, suponen 76 temporales marinos durante los treinta años analizados. Sin embargo, de estos eventos sólo se consideran aquellos cuya altura de Hs mantiene el umbral especificado durante al menos doce horas. De esta forma, como señalan Rangel y Anfuso (2014, p.41) "el temporal afecta la costa por lo menos durante un ciclo completo de marea", que en Canarias es de tipo semidiurno. Se descartan así los que presentan interrupciones importantes en los registros (Pardo, 1991; Yanes y Marzol, 2009), por lo que el número inicial de episodios se reduce a 73. Este número se limita, en última instancia, a 56 en aplicación del método de los valores extremos (Pot: Peak Over Threshold, Puertos del Estado, s.f.), según el cual han de transcurrir cinco días para que dos temporales marinos se consideren independientes.

Los temporales seleccionados se analizan mediante la confección de una base de datos integrada por campos tales como la fecha en la que se produjo el suceso, a la que se añaden el día previo a su inicio y el posterior a su finalización; el número de registros mayores o iguales al umbral de riesgo establecido; la duración del temporal en horas y la media de las alturas de la Hs y Hmax así como del Tp, L, dirección del oleaje y del viento dominante y velocidad de este último durante el desarrollo del episodio extremo (tabla 3 y 4 ).

El resultado del examen realizado evidencia, de un lado, que la frecuencia de las tormentas marinas en San Andrés es, por término medio, de dos eventos por año y que el $57,1 \%$ de las mismas ocurre en invierno, el $23,2 \%$ en primavera y el $19,6 \%$ en otoño (tabla 5). No ocurren en verano, al contrario de lo que sucede con las inundaciones costeras por rebase del oleaje; y, de otro lado, que su duración media suele ser de casi 2 días (47,6 horas), aunque hay temporales que superan los 3,5 (90 horas) llegando hasta un máximo de 6 (147 horas). En cualquier caso, estas situaciones de oleaje extremal se asocian a un swell del N $(32,1 \%)$ y NNE $(30,4 \%)$, con una Hs de 3 metros de altura media y 5,1 metros en el caso de la Hmax, 13 segundos de Tp y 286,2 metros de L. Refuerza el carácter distante del oleaje el hecho de que su desarrollo coincide con vientos locales del NNE $(19,6 \%)$ y NE $(14,3 \%)$ con una intensidad de $27,7 \mathrm{~km} / \mathrm{h}$. 
Determinación y caracterización de situaciones de temporal marino e inundación costera por rebase del oleaje en San Andrés,

Tabla 3. Temporales marinos considerados en San Andrés, Tenerife (1984-2014)

\begin{tabular}{|c|c|c|c|c|c|c|c|c|}
\hline \multirow[t]{2}{*}{ Fecha } & \multirow{2}{*}{$\begin{array}{c}\text { Duración } \\
\text { (horas) }\end{array}$} & \multirow{2}{*}{$\frac{\overline{\mathrm{H} s}}{\mathrm{~m}}$} & \multirow{2}{*}{$\frac{H_{\max }^{-}}{\mathrm{m}}$} & \multirow{2}{*}{$\frac{\overline{\mathrm{Tp}}}{\mathrm{s}}$} & \multirow{2}{*}{$\frac{\overline{\mathrm{L}}}{\mathrm{m}}$} & \multirow{2}{*}{$\begin{array}{c}\text { Vel.Vto } \\
\mathrm{km} / \mathrm{h}\end{array}$} & \multirow{2}{*}{$\begin{array}{c}\text { DirOlj } \\
\text { dominante }\end{array}$} & \multirow[t]{2}{*}{ DirVto dominante } \\
\hline & & & & & & & & \\
\hline 01-03/III/1985 & 24 & 2,8 & 4,8 & 8,8 & 122,2 & 32,1 & NNE & $\mathrm{NE}$ \\
\hline $25-31 / I I / / 1986$ & 66 & 2,9 & 5,0 & 11,5 & 223,0 & 32,5 & NNE & NNE-NE \\
\hline 29/03-01/IV/1987 & 27 & 2,9 & 5,0 & 10,3 & 165,6 & 31,7 & $\mathrm{NE}$ & NE \\
\hline 11-13/IV/1987 & 42 & 3,1 & 5,2 & 9,4 & 137,4 & 35,0 & $\mathrm{NE}$ & $\mathrm{NE}$ \\
\hline 07-09/II/1988 & 36 & 2,9 & 4,9 & 8,5 & 112,6 & 36,7 & NNE-NE & $\mathrm{NE}$ \\
\hline 11-14/II/1989 & 51 & 2,8 & 4,8 & 9,9 & 154,1 & 35,7 & NNE & NNE \\
\hline 27-30/XII/1989 & 27 & 3,3 & 5,7 & 13,0 & 267,1 & 41,6 & NNW-NW & NW \\
\hline $17-20 / / / 1994$ & 54 & 3,3 & 5,5 & 10,0 & 156,8 & 40,1 & NNE & NNE \\
\hline 02-05/IV/1994 & 45 & 3,2 & 5,4 & 9,8 & 152,2 & 37,1 & $\mathrm{NE}$ & $\mathrm{NE}$ \\
\hline $26-28 / 11 / 1995$ & 36 & 3,0 & 5,0 & 9,3 & 134,9 & 38,0 & NE-NNE & NE \\
\hline 31/XII/1997-02///1998 & 33 & 2,7 & 4,6 & 8,4 & 110,1 & 34,4 & NNE & NNE-NE \\
\hline 29-31/XII/1998 & 18 & 2,8 & 4,8 & 16,6 & 430,1 & 25,3 & NNW & $\mathrm{N}$ \\
\hline 07-13/I/1999 & 39 & 3,1 & 5,3 & 10,2 & 166,9 & 38,3 & E-N & ESE-NNW-NE \\
\hline 16-18/XII/1999 & 39 & 3,3 & 5,7 & 9,9 & 153,0 & 40,7 & $\mathrm{NE}$ & ENE \\
\hline $13-15 / \mathrm{XI} / 2005$ & 33 & 2,8 & 4,7 & 14,5 & 331,4 & 15,9 & $\mathrm{~N}$ & NNE-N \\
\hline $16-18 / / / 2006$ & 42 & 2,9 & 5,0 & 12,3 & 243,0 & 31,2 & $\mathrm{~N}$ & NNW-N-NNE \\
\hline $25-29 / / / 2006$ & 54 & 2,8 & 4,7 & 14,2 & 327,2 & 23,7 & NNW-N & WNW \\
\hline 13-21/II/2006 & 54 & 2,9 & 4,9 & 16,2 & 414,7 & 25,2 & $\mathrm{~N}$ & NNE-N \\
\hline 27/02-07/III/2006 & 69 & 2,9 & 5,0 & 10,6 & 180,6 & 38,3 & $\mathrm{~N}$ & NNW-NE \\
\hline $25-29 / \mathrm{XI} / 2006$ & 66 & 2,9 & 4,9 & 16,3 & 416,7 & 20,2 & NNW-N & NE \\
\hline $22-24 / \mathrm{II} / 2007$ & 27 & 2,8 & 4,7 & 17,5 & 480,2 & 13,3 & NNW & N-NNE \\
\hline 08-10/III/2007 & 39 & 3,1 & 5,2 & 9,7 & 146,3 & 36,1 & NNE & NNE-NE \\
\hline 19-23/III/2007 & 54 & 3,3 & 5,6 & 13,7 & 309,9 & 32,6 & NNE & NNE-NE \\
\hline 02-04/XII/2007 & 27 & 2,8 & 4,8 & 18,3 & 525,2 & 22,4 & $\mathrm{~N}$ & NE-NNE \\
\hline 03-06/I/2008 & 42 & 3,3 & 5,7 & 16,9 & 450,7 & 25,0 & $\mathrm{~N}$ & NNW-NE \\
\hline 10-13/III/2008 & 42 & 2,8 & 4,8 & 14,7 & 365,7 & 26,8 & $\mathrm{~N}$ & NNE \\
\hline 30/03-02/IV/2008 & 39 & 3,0 & 5,1 & 9,2 & 131,8 & 36,1 & NNE & NE \\
\hline $28-30 / \mathrm{X} / 2008$ & 30 & 2,9 & 4,9 & 10,2 & 164,1 & 38,0 & NNE & NNE-N \\
\hline 14-16/XII/2008 & 33 & 3,0 & 5,1 & 15,2 & 364,5 & 34,1 & $\mathrm{~N}$ & $\mathrm{~N}$ \\
\hline $15-27 / \mathrm{I} / 2009$ & 108 & 3,1 & 5,3 & 16,5 & 426,1 & 28,8 & $\mathrm{~N}$ & N-NNE \\
\hline 01-03/II/2009 & 33 & 3,3 & 5,6 & 15,1 & 357,6 & 27,9 & NNW-N & WNW-NW \\
\hline 05-08/III/2009 & 51 & 2,8 & 4,8 & 15,7 & 392,1 & 29,2 & N-NNE & NNE-NE \\
\hline $08-10 / \mathrm{XI} / 2009$ & 21 & 2,8 & 4,8 & 9,0 & 127,3 & 34,0 & NNE & NE-NNE \\
\hline 02-04/III/2010 & 18 & 2,8 & 4,7 & 14,5 & 328,8 & 20,6 & NNW & WNW \\
\hline 03-05/IV/2010 & 33 & 2,9 & 4,9 & 9,1 & 130,2 & 36,9 & NNE & NNE \\
\hline $09-11 / \mathrm{X} / 2010$ & 24 & 2,9 & 4,8 & 16,7 & 437,1 & 11,7 & $\mathrm{~N}$ & WNW \\
\hline $31 / 10-03 / \mathrm{XI} / 2010$ & 63 & 2,8 & 4,7 & 11,5 & 217,4 & 32,4 & N-NNE & NNE \\
\hline 09-11/XI/2010 & 33 & 3,2 & 5,5 & 18,3 & 521,8 & 13,1 & $\mathrm{~N}$ & NNE-ENE \\
\hline $11-18 / \mathrm{II} / 2011$ & 75 & 2,9 & 5,0 & 17,2 & 466,0 & 23,1 & $\mathrm{~N}$ & N-NNE \\
\hline 29/10-04/XI/2011 & 42 & 2,8 & 4,7 & 17,1 & 458,2 & 21,4 & N-NNW & NE-SW-W \\
\hline 12-17/XII/2011 & 45 & 2,8 & 4,8 & 17,7 & 491,4 & 21,1 & $\mathrm{~N}$ & NE-ENE \\
\hline 03-05/I/2012 & 27 & 2,7 & 4,6 & 18,2 & 515,6 & 12,0 & N-NNE & E-ESE \\
\hline 04-06/II/2012 & 45 & 3,2 & 5,5 & 9,9 & 152,1 & 26,7 & NNE & NE-ENE \\
\hline $11-13 / X I / 2012$ & 30 & 2,7 & 4,5 & 9,2 & 131,8 & 21,9 & $\mathrm{~N}$ & NNE-NE \\
\hline 01-03/XII/2012 & 27 & 2,8 & 4,7 & 11,4 & 201,9 & 23,8 & NNE & NNE \\
\hline $22-25 / 1 / 2013$ & 63 & 3,0 & 5,1 & 16,6 & 431,3 & 23,4 & $\mathrm{~N}$ & NNE \\
\hline 03-09/II/2013 & 66 & 2,8 & 4,7 & 10,0 & 155,2 & 22,7 & NNE & NNE \\
\hline $28-30 / X / 2013$ & 42 & 2,9 & 4,8 & 14,4 & 347,5 & 22,2 & $\mathrm{~N}$ & NNE-N \\
\hline $13-15 / X I I / 2013$ & 21 & 2,7 & 4,6 & 9,0 & 135,2 & 20,6 & NNE & NNE \\
\hline 20-31/XII/2013 & 123 & 3,0 & 5,1 & 12,8 & 283,7 & 20,4 & NNE-N & NE-NNE \\
\hline 05-08/I/2014 & 39 & 3,4 & 5,7 & 19,4 & 592,4 & 7,2 & $\mathrm{~N}$ & SE-E \\
\hline $17-31 / 1 / 2014$ & 147 & 3,2 & 5,5 & 13,3 & 291,6 & 25,9 & N-NNE & NE-NW \\
\hline 14-19/II/2014 & 90 & 3,2 & 5,5 & 14,2 & 328,2 & 27,7 & $\mathrm{~N}$ & $\mathrm{~N}$ \\
\hline 25/II-07/III/2014 & 117 & 3,1 & 5,3 & 13,4 & 301,3 & 23,4 & NNE & NNE \\
\hline $25-27 / 111 / 2014$ & 42 & 2,8 & 4,7 & 9,8 & 149,7 & 22,6 & NNE & NNE \\
\hline 27/XI-01/XII/2014 & 54 & 3,9 & 6,6 & 14,3 & 320,7 & 31,0 & N-NNW & NNW-WNW \\
\hline
\end{tabular}

Fuente: Puertos del Estado. Elaboración propia. 
Tabla 4. Cronograma anual, estacional y mensual de los temporales marinos y de su Hs en San Andrés, Tenerife (1984-2014)

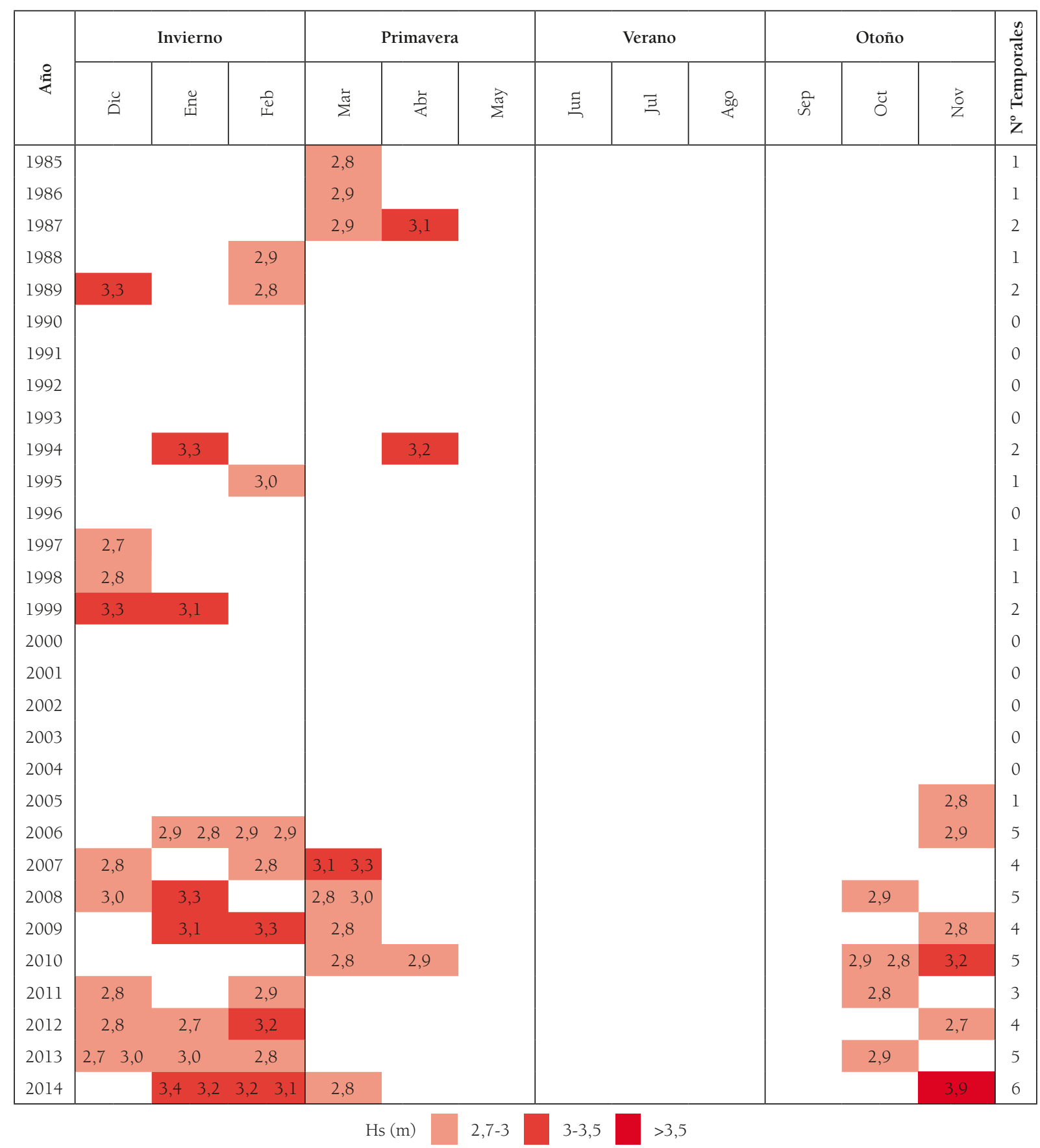

Fuente: Puertos del Estado. Elaboración propia.

Dentro de esta tónica general, los valores consignados experimentan, sin embargo, algunos pequeños cambios según la época del año. En este sentido, destacan en invierno la mayor duración de los temporales -prácticamente 3 días (53,3 horas)-, el protagonismo del swell del N (37,5\%), con la llegada de olas de 306,3 metros de L, y el incremento de la velocidad del viento con rachas máximas de hasta $40 \mathrm{~km} / \mathrm{h}$. En primavera, lo más notorio es la finalización de las tormentas 1,5 días después de su inicio y la constancia del swell del NNE (53,8\%). Este se combina, además, con un sea ligado, sobre todo, a vientos del $\mathrm{NE}(38,5 \%)$ de $31,5 \mathrm{~km} / \mathrm{h}$ de media. Por último, los temporales de otoño se prolongan durante poco más de 1,5 días (39,8 horas), tiempo a lo largo del cual predomina un swell del $\mathrm{N}(45,5 \%)$ con olas de 315,8 metros de L. Los vientos dominantes son, por su parte, del NNE-N (27,3\%). 
Tabla 5. Temporales marinos en San Andrés, Tenerife, según meses y estación del año (1984-2014)

\begin{tabular}{|c|c|c|c|c|}
\hline Estación & Meses & $\mathrm{N}^{0}$ Temporales & Total & $\%$ \\
\hline \multirow{3}{*}{ Invierno } & Diciembre & 9 & \multirow{3}{*}{32} & \multirow{3}{*}{57,1} \\
\hline & Enero & 11 & & \\
\hline & Febrero & 12 & & \\
\hline \multirow{3}{*}{ Primavera } & Marzo & 10 & \multirow{3}{*}{13} & \multirow{3}{*}{23,2} \\
\hline & Abril & 3 & & \\
\hline & Mayo & 0 & & \\
\hline \multirow{3}{*}{ Verano } & Junio & 0 & \multirow{3}{*}{0} & \multirow{3}{*}{0,0} \\
\hline & Julio & 0 & & \\
\hline & Agosto & 0 & & \\
\hline \multirow{3}{*}{ Otoño } & Septiembre & 0 & \multirow{3}{*}{11} & \multirow{3}{*}{19,6} \\
\hline & Octubre & 4 & & \\
\hline & Noviembre & 7 & & \\
\hline \multicolumn{2}{|c|}{ Total } & 56 & 56 & 100 \\
\hline
\end{tabular}

Fuente: Puertos del Estado. Elaboración propia.

\section{Discusión}

A partir de los resultados obtenidos, expuestos en el anterior apartado, es posible establecer los patrones que concurren en la génesis y desarrollo de los riesgos vinculados al mar en San Andrés. Así, el análisis de situaciones representativas de tempestad en el mar y rebase del oleaje proporcionan una visión más precisa de las inundaciones costeras y sus efectos en el área de estudio. La selección de estas situaciones responde a lo singular de la dinámica del oleaje y viento y a la constatación de sus secuelas a través de la prensa.

La discriminación de los temporales marinos se realiza atendiendo a su mayor o menor duración y continuidad, así como a la evolución de los valores medios, máximo y mínimo de la altura de la Hs y del Tp durante el transcurso del episodio, lo que se hace extensivo a la velocidad del viento. Se tiene en cuenta, además, el hecho de que la dirección de oleaje y viento pueda no ser coincidente. La combinación de estos criterios permite la elección de nueve situaciones. No obstante, se contempla un décimo temporal marino por los graves daños producidos en el litoral insular (Criado \& Dorta, 2003). Estos diez eventos se clasifican según la situación atmosférica que los origina (Tros de Ilarduya, 2005; Yanes et al., 2007). De ello resulta que el 80\% corresponde a una inestabilidad acusada en Islandia o al NW de Gran Bretaña y el $20 \%$ a una configuración barométrica también muy inestable en Canarias.

El papel de la prensa escrita es notable a la hora de analizar las inundaciones costeras por rebase del oleaje, pues los registros de los modelos SIMAR no permiten identificarlas y explicar por sí mismos las causas que concurren en su génesis. El manejo de esta fuente es muy útil al dejar constancia de sucesos que acontecen en verano, cuando el oleaje en San Andrés se define por su moderación. Por ello, el rango mareal y los cambios de las olas en aguas someras son factores a considerar en su análisis. Las fechas elegidas obedecen a la repercusión mediática del evento, por lo que se tienen en cuenta el volumen de datos e imágenes sobre los perjuicios acarreados y su aparición en portada o páginas interiores.

En los apartados siguientes se procede al análisis de dos situaciones de temporal marino y dos de inundación costera por rebase del oleaje, al margen de la fecha en la que se producen y en función de su intensidad.

\subsection{Situaciones de temporal marino}

Los temporales registrados el 8-12/I/1999 y el 6-8/I/2014 muestran con claridad los peligros asociados al mar a los que está expuesto San Andrés. Ambos responden a un patrón hidrodinámico y atmosférico específico, cuyos principales rasgos se reseñan a continuación. 
a) Temporal de 8-12/I/1999: Las modificaciones experimentadas por las olas con respecto a su régimen habitual entre el 8 y 12 de enero de 1999 resultan de un temporal marino caracterizado por su duración, irregularidad y ascensos y descensos marcados de los parámetros del oleaje en lapsos de tiempo cortos. Apunta en este sentido el hecho de que, si bien entre esos días son 39 las horas durante las cuales la ola significante iguala o supera el umbral establecido, el temporal se desarrolla en dos fases: la primera tiene lugar entre las 00:00 y 18:00 horas del día 8 y la segunda entre las 6:00 y 21:00 del 12 aunque con cierta prolongación hasta primeras horas del 13 de enero (fig. 2).

Figura 2. Temporal marino del 8-12/1/1999 en San Andrés, Tenerife

A

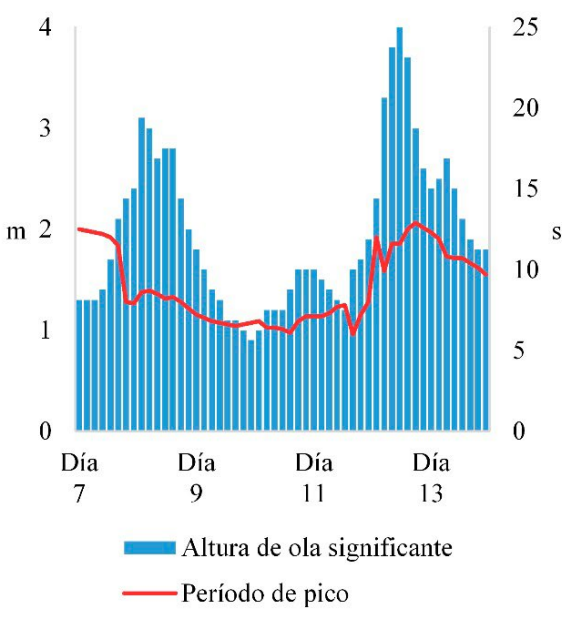

C

\begin{tabular}{|c|c|c|c|c|c|c|c|c|c|}
\hline \multirow{2}{*}{ Parámetros } & \multicolumn{3}{|c|}{ Día previo (Día 7) } & \multicolumn{3}{c|}{ Primer centro temporal (Día 8) } & \multicolumn{3}{c|}{ Transición (Días 9 y 11) } \\
\cline { 2 - 10 } & Media & Max & Min & Media & Max & Min & Media & Max & Min \\
\hline Hs (m) & 1,7 & 2,4 & 1,3 & 2,7 & 3,1 & 2,0 & 1,4 & 1,9 & 0,9 \\
\hline Hmax (m) & 2,9 & 4,1 & 2,2 & 4,6 & 5,3 & 3,4 & 2,3 & 3,2 & 1,5 \\
\hline Tp (s) & 11,1 & 12,5 & 7,9 & 8,3 & 8,7 & 7,6 & 6,9 & 8,0 & 6,0 \\
\hline L (m) & 197,5 & 243,8 & 97,4 & 106,7 & 118,1 & 90,1 & 74,1 & 99,8 & 56,2 \\
\hline Dirolj & \multicolumn{3}{|c|}{ NW-ENE } & \multicolumn{3}{|c|}{ E } \\
\hline DirV & \multicolumn{3}{|c|}{ ESE-ENE-E } & \multicolumn{3}{|c|}{ ESE } & \multicolumn{4}{c|}{ N-NNE } \\
\hline VelV (km/h) & 26,0 & 41,4 & 17,3 & 39,1 & 45,4 & 29,9 & 22,7 & 33,5 & 12,2 \\
\hline
\end{tabular}

\begin{tabular}{|c|c|c|c|c|c|c|}
\hline \multirow{2}{*}{ Parámetros } & \multicolumn{3}{|c|}{ Segundo centro te mporal (Día 12) } & \multicolumn{3}{c|}{ Día poste rior (Día 13) } \\
\cline { 2 - 7 } & Media & Max & Min & Media & Max & Min \\
\hline Hs $(\mathrm{m})$ & 3,1 & 4,0 & 2,0 & 2,2 & 2,7 & 1,8 \\
\hline Hmax $(\mathrm{m})$ & 5,2 & 6,8 & 3,4 & 3,7 & 4,6 & 3,1 \\
\hline Tp (s) & 11,7 & 12,9 & 9,9 & 10,8 & 12,3 & 9,7 \\
\hline L $(\mathrm{m})$ & 216,3 & 259,6 & 152,9 & 183,8 & 236,0 & 146,8 \\
\hline Dirolj & \multicolumn{3}{|c|}{$\mathrm{N}-\mathrm{NNE}$} & \multicolumn{3}{c|}{$\mathrm{NNE}$} \\
\hline DirV & \multicolumn{3}{|c|}{$\mathrm{NE}-\mathrm{NNW}$} & \multicolumn{3}{|c|}{$\mathrm{NNE}$} \\
\hline VeV $(\mathrm{km} / \mathrm{h})$ & 36,1 & 50,8 & 21,6 & 27,1 & 34,9 & 24,5 \\
\hline
\end{tabular}

B

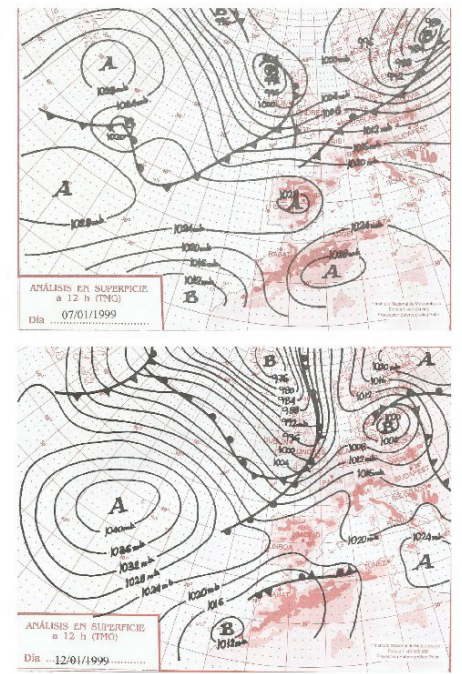

A) Evolución del comportamiento del oleaje; B) Configuración atmosférica en superficie los días 7 y 12; C) Valores del oleaje y viento.

Fuente: Puertos del Estado y [AEMET]. Elaboración propia.

El paso brusco de un swell a un sea del 7 al 8 de ese mes marca el inicio del fenómeno en estudio, al caer el Tp de una media de 11,2 segundos a un valor mínimo de 7,6, mientras la altura media de la Hs sube de 1,7 a 2,7 metros, llegando incluso a un máximo de 3,1 y la Hmax, por su parte de 2,9 a 4,6 metros. Tal cambio es fruto de una configuración atmosférica conformada por una familia de borrascas (992 $\mathrm{hPa}$ ) al NW de Irlanda y de la localización sobre Canarias de una depresión poco profunda en superficie (1012 hPa). Su giro ciclónico determina que las olas inicialmente del NW-ENE rolen al E al tiempo que son cada vez más cortas, pues apenas alcanzan el centenar de metros de longitud. Por su parte, el viento adquiere una componente ESE y aumenta su fuerza, cifrada el día 8 en 39,1 km/h de media y 45,4 de máxima, aunque con rachas de hasta $70-80 \mathrm{~km} / \mathrm{h}$ (Criado \& Dorta, 2003).

Esta situación de sea se mantiene entre el 9 y 11 de enero en relación con la llegada del Anticiclón de las Azores, al que se debe que oleaje y viento procedan del N-NNE. La estabilidad atmosférica sobre Canarias a partir del día 10 conlleva una caída de los valores de los parámetros en análisis, de modo que 
la altura media de la Hs es de 1,4 metros, el Tp de 6,9 segundos, la L de 74,1 metros y el viento de 22,7 $\mathrm{km} / \mathrm{h}$. La sólida instalación y potencia de ese anticiclón entre $35^{\circ} \mathrm{N}$ y $35^{\circ} \mathrm{W}(1040 \mathrm{hPa})$ y la presencia de una baja presión (1012 hPa) en el Golfo de Cádiz favorecen el 12 de enero la combinación de un swell del N-NNE y de un sea con vientos fuertes del NE-NNW que de una media de $36,1 \mathrm{~km} / \mathrm{h}$ llegan a un máximo de 50,8. La altura de la Hs aumenta con rapidez de 2,3 a 3,3 metros entre las 3:00 y 6:00 horas de ese día, si bien a las 12:00 ya es de 4 metros mientras la Hmax es de 6,8; por su parte el Tp alcanza 12,9 segundos y la L 259,6 metros. En esta situación hay que considerar, al igual que en la primera fase del temporal, los fenómenos asociados al wind setup (Benavente, Bello, Anfuso, Nachite y Macías, 2007), en cuanto propician una sobreelevación del nivel del mar, y la sucesión de pleamares. A partir del día 13, el swell se modera de forma progresiva.

Las secuelas del temporal son de diversa índole. En San Andrés, el mal estado del mar obliga a cerrar la Avenida Marítima al tráfico y resguardar las barcas de pesca, mientras en la Playa de Las Teresitas las fuertes rachas de viento desplazan un importante volumen de arena al aparcamiento existente en su parte posterior. La severidad de los daños es muy notoria en el frente marítimo de Santa Cruz de Tenerife, cuyas pérdidas se calculan, según El Día, en 2.400 millones de pesetas (más de 14 millones de euros). Al igual que otros muchos enclaves del litoral este-sureste de la isla, las infraestructuras portuarias no están preparadas para soportar vientos intensos, sobre todo del segundo cuadrante (Criado \& Dorta, 2003). Lo avalan la rotura de más de 15 metros del dique de protección del Parque Marítimo, la pérdida de la mayoría de las embarcaciones del Centro Superior de Náutica y de la Escuela de Vela del Cabildo de Tenerife y la desaparición de más de 80 vehículos en el mar.

b) Temporal de 6-8/I/2014: La regularidad y la continuidad definen el temporal ocurrido entre el 6 y 8 de enero de 2014, a causa de una borrasca muy profunda $(944 \mathrm{hPa})$ situada al W de las Islas Británicas. Su desarrollo tiene lugar entre las 12:00 horas del día 6 y las 00:00 horas del 8, tiempo en el que las oscilaciones de oleaje y viento son graduales (fig. 3).

Figura 3.Temporal marino del 6-8/I/2014 en San Andrés, Tenerife

$$
4
$$

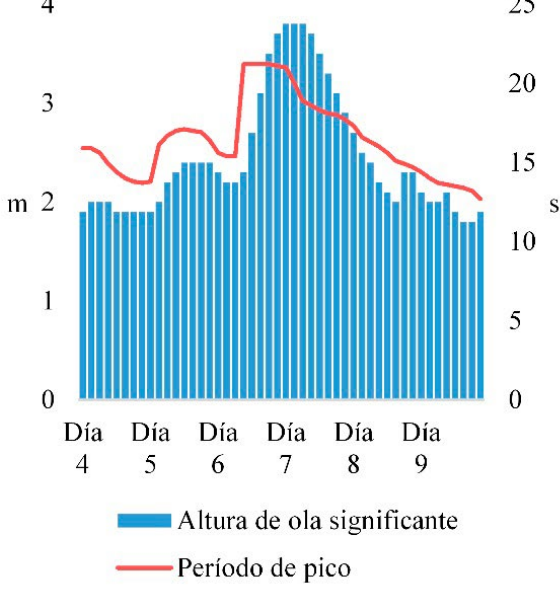

C

\begin{tabular}{|c|c|c|c|c|c|c|c|c|c|}
\hline \multirow{2}{*}{ Parámetros } & \multicolumn{3}{|c|}{ Días previos (Días 4 y 5 ) } & \multicolumn{3}{|c|}{ Centro temporal (Días 6-8) } & \multicolumn{3}{|c|}{ Días posteriores (Días 9 y 10 ) } \\
\hline & Media & $\operatorname{Max}$ & Min & Media & Max & $\mathrm{Min}$ & Media & $\operatorname{Max}$ & Min \\
\hline Hs (m) & 2,1 & 2,4 & 1,9 & 2,9 & 3,8 & 2,0 & 1,8 & 2,1 & 1,4 \\
\hline Hmax (m) & 3,6 & 4,1 & 3,2 & 4,8 & 6,5 & 3,4 & 3,1 & 3,6 & 2,4 \\
\hline $\mathrm{Tp}(\mathrm{s})$ & 15,6 & 17,1 & 13,7 & 17,9 & 21,2 & 14,7 & 12,7 & 14,4 & 11,5 \\
\hline $\mathrm{L}(\mathrm{m})$ & 380,8 & 456,2 & 292,8 & 507,7 & 701,1 & 337,1 & 253,9 & 323,5 & 206,3 \\
\hline Dirolj & \multicolumn{3}{|c|}{$\mathrm{N}-\mathrm{NNW}$} & \multicolumn{3}{|c|}{$\mathrm{N}-\mathrm{NNW}$} & \multicolumn{3}{|c|}{ NNW } \\
\hline DirV & \multicolumn{3}{|c|}{ NNE-NE-ENE } & \multicolumn{3}{|c|}{ ENE-E-SW } & \multicolumn{3}{|c|}{ N-NNW } \\
\hline VelV $(\mathrm{km} / \mathrm{h})$ & 12,2 & 18,0 & 8,6 & 8,3 & 16,6 & 3,2 & 11,9 & 26,3 & 4,7 \\
\hline
\end{tabular}

A) Evolución del comportamiento del oleaje; B) Configuración atmosférica en superficie los días 5 y 8; C) Valores del oleaje y viento.

Fuente: Puertos del Estado y [AEMET]. Elaboración propia.

En efecto, el aumento de la altura media de la Hs de 2,1 a 2,9 metros y de la Hmax de 3,6 a 4,8 metros, así como del Tp de 15,6 a 17,9 segundos y de la L de 380,8 a 507,7 metros se produce a lo largo del 4,5 
y parte del 6 de enero. Ello coincide con la llegada de un swell del N-NNW a Canarias, donde la estabilidad atmosférica impuesta por el Anticiclón de las Azores comporta vientos del primer cuadrante de 12,2 $\mathrm{km} / \mathrm{h}$. Esta situación se refuerza en el transcurso del día 7, cuando en ciertos momentos las Hs y Hmax, el Tp y la L llegan hasta 3,8 y 6,5 metros, 21,2 segundos y 701 metros, respectivamente. La persistencia de las altas presiones en el ámbito del archipiélago explica la reducida intensidad de los vientos locales, que, con rumbos ENE-E-SW, arrojan un valor medio de tan solo $8,3 \mathrm{~km} / \mathrm{h}$; es más, su mínimo, aunque puntual, se cifra en $3,2 \mathrm{~km} / \mathrm{h}$. En los días posteriores, se mantiene el swell del NNW, aunque con olas de 1,8 metros de Hs y 12,7 segundos de Tp. Lo moderado de tales valores obedece, en parte, al relleno de la borrasca (1001 hPa) durante el 7 y 8 de enero. Al mismo tiempo, la localización de una baja presión $(1011 \mathrm{hPa})$ al $\mathrm{N}$ de Canarias hace que los vientos dominantes del N-NNW sean, por término medio, de $11,9 \mathrm{~km} / \mathrm{h}$.

Las referencias en la prensa señalan daños generalizados y cuantiosos en el norte de Tenerife, con especial incidencia en el entorno del Macizo de Anaga (Diario de Avisos, 2014; El Día, 2014). No obstante, las consecuencias en San Andrés no revisten la gravedad alcanzada en esos otros puntos costeros de la isla.

\subsection{Situaciones de rebase del oleaje}

La sobreelevación del nivel del mar puede constituir un fenómeno costero adverso desde el momento en que acarrea inundaciones, como las ocurridas en San Andrés el 29-31/VIII/2011 y el 26-27/VIII/1996. La disminución de la seguridad de su población y la alteración de la dinámica socioeconómica exigen la consideración de sus aspectos más destacados, a lo que se procede seguidamente.

a) Rebase del oleaje 29-31/VIII/2011: De los cinco episodios de inundación costera acontecidos en San Andrés en los últimos años (2/VIII/2007, 23/XII/2010, 14/V/2011, 30/VIII/2011 y 6/II/2012 en Mora et al., 2013), el que se examina es uno de los de mayor impronta en función de la magnitud del rebase, desperfectos originados y repercusión mediática. En efecto, las olas que invaden San Andrés desbordan con mucho el ámbito de la Avenida Marítima. A diferencia de otras ocasiones en las que el agua del mar se limita a abrir socavones en su escollera e inundar algunos restaurantes (23/XII/2010 y 6/II2012 en Mora et al., 2013), en este episodio avanza 80 metros hacia el interior de la localidad (Cordobés, 2014). Su incidencia es muy notable sobre todo en el entorno del Castillo de San Andrés y sus inmediaciones, donde el agua alcanza un metro de altura en al menos cinco viviendas y en varios comercios y restaurantes, mientras quince vehículos quedan inservibles. El Servicio Provincial de Costas repara el talud mediante procedimiento de urgencia, con un coste de 409.602,49 euros que aporta el Gobierno de España (Cordobés, 2014).

La información consultada (Diario de Avisos, El Día, La Opinión de Tenerife y La Provincia; Cordobés, 2014) señala que el fenómeno comienza a evidenciarse sobre la 1:00 de la madrugada del día 29, aunque es entre las 13:00 y 14:00 horas de ese día cuando se produce el mayor sobrepaso del mar con respecto a los de horas posteriores. Durante el desarrollo de este episodio, los registros de oleaje evidencian el carácter moderado y bastante uniforme de las Hs y Hmax, pues ya desde el día 27 su altura media se mantiene en 1,1 y 1,9 metros. El Tp es, sin embargo, fluctuante, al pasar con rapidez de 6,5 a 11,8 segundos a finales del 27 y comienzo del 28 de agosto y descender con brusquedad hasta un mínimo de 6,1 segundos el día 29 , registro que no varía hasta que acaba la inundación. Tal oscilación denota la sustitución de un swell por un sea dada la persistencia de una situación anticiclónica en Canarias, donde la estabilidad atmosférica se materializa en vientos del NNE-NE con una velocidad media de 17,8 km/h (fig. 4).

La similitud de dichos valores a los del régimen habitual en verano determina que las olas no sean el factor desencadenante de este episodio. Aunque en San Andrés las inundaciones costeras coincidan a veces con una Hs superior al umbral de riesgo de temporal marino establecido (14/V/2011 y 6/1I/2012 en Mora et al., 2013), la causa del avance del mar remite, en lo esencial, a la marea. En la de agosto de 2011 el hecho a valorar es, concretamente, el nivel alcanzado por la pleamar en una fase de mareas vivas equinocciales. El mismo es alto considerando que en la madrugada del día 29 es de 2,6 metros, de 2,8 a las 14:00 horas y de 2,9 a las 15:00 de los días 30 y 31 . Por su parte, el vaciado de la marea es apreciable toda vez que la bajamar es, en ciertos momentos, de sólo 0,4 metros. Pero más allá de la amplitud del rango mareal, lo significativo es la concentración del rebase del oleaje en un lapso temporal breve.

Otro aspecto a estimar, en este contexto, es la canalización de las olas hacia la escollera de la Avenida Marítima de San Andrés. Los registros de los modelos SIMAR apuntan el predominio de un oleaje del NNE del 27 al 31 de agosto. Este alcanzaría esa escollera tras la modificación impuesta a su dirección inicial por la península de Anaga, el dique de la Playa de Las Teresitas y el espigón de la Cofradía de Pescadores existente en las inmediaciones de dicha playa. Sin embargo, estudios recientes señalan que entre 
las 13:00 y las 15:00 horas del día 29 las olas proceden del SSE (Mora et al., 2013; Cordobés, 2014), lo que supone su avance directo hacia el área de estudio. A ello contribuye la difracción que introduce el saliente costero creado con terreno ganado al mar (2006) en el extremo suroeste de esa Avenida, para el emplazamiento del Centro Oceanográfico de Canarias. Conviene tener en cuenta, además, la concurrencia de lo que se podría estimar como causas secundarias, caso de la reflexión de la ola que propicia el espigón de la Cofradía de Pescadores; de la desembocadura del barranco del Cercado, que facilita el avance del mar hacia el Castillo de San Andrés, el sector más bajo del caserío; y, por último, de la cada vez menor capacidad de la escollera exterior de la Avenida Marítima para reducir, como apunta González Fariñas, el embate de las olas ante la sucesión de desperfectos (Diario de Avisos, 10/IX/2011).

Figura 4. Inundación costera por rebase del oleaje de 29-31/VIII/2011 en San Andrés, Tenerife

A

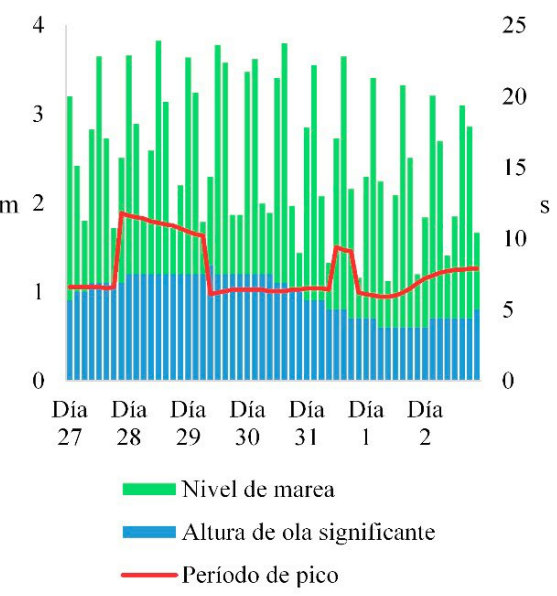

C

\begin{tabular}{|c|c|c|c|c|c|c|c|c|c|}
\hline \multirow{2}{*}{ Paráme tros } & \multicolumn{3}{|c|}{ Dias previos ( Dias 27 y 28) } & \multicolumn{3}{|c|}{ Centro de inundación (Dias 29-31) } & \multicolumn{3}{|c|}{ Dias posteriores (Dias 1 y 2 ) } \\
\hline & Media & $\operatorname{Max}$ & $\mathrm{Min}$ & Media & Max & Min & Media & Max & $\mathrm{Mim}$ \\
\hline Nivel de marea (m) & 1,5 & 2,6 & 0,5 & 1,6 & 2,9 & 0,4 & 1,6 & 2,7 & 0,5 \\
\hline \begin{tabular}{|l|} 
Hs (m) \\
\end{tabular} & 1,1 & 1,2 & 0,9 & 1,1 & 1,3 & 0,7 & 0,7 & 0,8 & 0,6 \\
\hline $\operatorname{Hmax}(\mathrm{m})$ & 1,9 & 2,0 & 1,5 & 1,8 & 2,2 & 1,2 & 1,1 & 1,4 & 1,0 \\
\hline $\operatorname{Tp}(\mathrm{s})$ & 9,2 & 11,8 & 6,5 & 7,2 & 10,5 & 6,1 & 6,9 & 7,9 & 5,9 \\
\hline $\mathrm{L}(\mathrm{m})$ & 140,7 & 217,2 & 65,9 & 84,7 & 172,0 & 58,0 & 75,8 & 97,4 & 54,3 \\
\hline DirOlj & \multicolumn{3}{|c|}{ NNE } & \multicolumn{3}{|c|}{ NNE } & \multicolumn{3}{|c|}{$\mathrm{N}$} \\
\hline DirVto & \multicolumn{3}{|c|}{ NNE-NE } & \multicolumn{3}{|c|}{ NNE } & \multicolumn{3}{|c|}{ WNW } \\
\hline Velv $(\mathrm{km} / \mathrm{h})$ & 17,8 & 21,6 & 13,3 & 18,7 & 26,3 & 8,3 & 8,6 & 19,8 & 2,2 \\
\hline
\end{tabular}

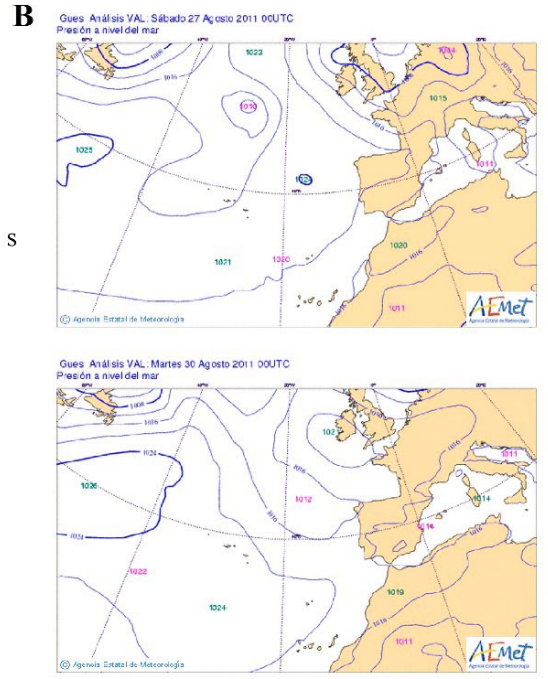

A) Evolución del comportamiento del oleaje y nivel de marea; B) Configuración atmosférica en superficie los días 27 y 30 ; C) Valores del oleaje, viento y mareas

Fuente: Puertos del Estado y [AEMET]. Elaboración propia.

b) Rebase del oleaje 26-27/VIII/1996: Las cuestiones reseñadas en la inundación de agosto de 2011 se reconocen en la que ahora se trata. En primer lugar, porque los daños producidos comportan el cierre de la Avenida Marítima al tráfico rodado por el arrastre de grandes piedras por parte de las olas y la anegación de varias viviendas, dos de ellas localizadas en las inmediaciones del Castillo de San Andrés; y, en segundo lugar, por el protagonismo de la marea ante el oleaje.

La particularidad de este episodio de rebase deriva no solo del comportamiento muy regular del oleaje, sino también de la correlación directa entre Hs y Tp, de modo que el aumento o disminución progresiva de aquella es simultáneo con el de este. En cualquier caso, ambos parámetros se caracterizan por la moderación y continuidad de sus registros, al mantenerse en torno a un valor medio de 1,2 metros y 7,2 segundos desde prácticamente las horas finales del día 25 hasta el 29. No es el caso de la pleamar en cuanto que supera, en ciertos momentos, los 2,5 metros (fig. 5). Como recoge la prensa, en San Andrés se produce un primer rebase entre las 22:00 horas del día 26 y las 5:00 del 27, coincidiendo con una marea alta de 2,2 metros de media desde el comienzo hasta las 2:00 horas. El fenómeno se repite a las 12:00 horas de este último día constituyendo la fase central de la inundación, ya que el ascenso de la marea llega a 2,7 metros. En esta fase, el rango mareal es notable, al ser la diferencia entre la pleamar máxima y la bajamar mínima de 2,2 metros. 
Durante el desarrollo de esta inundación, la persistencia de un sea del N-NNE es un hecho a destacar en relación con la localización del Anticiclón de la Azores (1020 hPa) al NW de Canarias y la existencia de una baja presión sobre el continente africano poco profunda (1008 hPa). Tal configuración da lugar desde el 25 de agosto a vientos con una intensidad media en torno a $23 \mathrm{~km} / \mathrm{h}$. Estos se mantienen en los días posteriores a la inundación aunque con una dirección dominante del NE, fruto de la instalación de dicho anticiclón al NW de la Península Ibérica. Con todo, lo más significativo es la procedencia del oleaje: siendo del primer cuadrante, como consta en los modelos SIMAR, su incidencia en San Andrés debe responder durante esta inundación a mecanismos similares a los contemplados en la de 2011, al menos por lo que respecta a la modificación que introducen en el avance de las olas la propia configuración costera y las construcciones que la jalonan. Si su origen es, por el contrario, del E o SE, la explicación del rebase es lo ya señalado también en el caso anterior, con la salvedad impuesta por la inexistencia entonces del saliente costero en el que se ubica el Centro Oceanográfico de Canarias.

Figura 5. Inundación costera por rebase del oleaje de 26-27/VIII/1996 en San Andrés, Tenerife

A

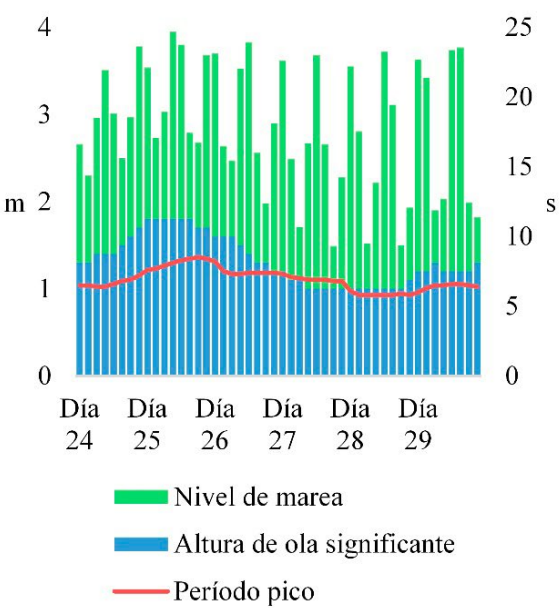

C

\begin{tabular}{|c|c|c|c|c|c|c|c|c|c|}
\hline \multirow{2}{*}{ Parámetros } & \multicolumn{3}{|c|}{ Días previos (Días 24 y 25) } & \multicolumn{3}{|c|}{ Centro de inundación (Días 26 y 27) } & \multicolumn{3}{|c|}{ Días posteriores (Días 28 y 29) } \\
\hline & Media & Max & Min & Media & Max & Min & Media & Max & Min \\
\hline Nivel de marea (m) & 1,5 & 2,2 & 0,9 & 1,5 & 2,7 & 0,5 & 1,5 & 2,7 & 0,5 \\
\hline $\mathrm{Hs}(\mathrm{m})$ & 1,6 & 1,8 & 1,3 & 1,2 & 1,6 & 1,0 & 1,1 & 1,3 & 1,0 \\
\hline Hmax (m) & 2,7 & 3,1 & 2,2 & 2,1 & 2,7 & 1,7 & 1,9 & 2,2 & 1,7 \\
\hline $\mathrm{Tp}(\mathrm{s})$ & 7,4 & 8,5 & 6,4 & 7,2 & 8,2 & 6,8 & 6,1 & 6,6 & 5,8 \\
\hline $\mathrm{L}(\mathrm{m})$ & 86,1 & 112,7 & 63,9 & 81,6 & 104,9 & 72,1 & 58,9 & 68,0 & 52,5 \\
\hline DirOlj & \multicolumn{3}{|c|}{ NE } & \multicolumn{3}{|c|}{ NNE } & \multicolumn{3}{|c|}{$\mathrm{NE}$} \\
\hline DirVto & \multicolumn{3}{|c|}{ NNE } & \multicolumn{3}{|c|}{ NNE-NE } & \multicolumn{3}{|c|}{$\mathrm{NE}$} \\
\hline VelV $(\mathrm{km} / \mathrm{h})$ & 28,3 & 31,0 & 25,9 & 22,9 & 28,8 & 19,4 & 23,0 & 26,3 & 20,5 \\
\hline
\end{tabular}

B

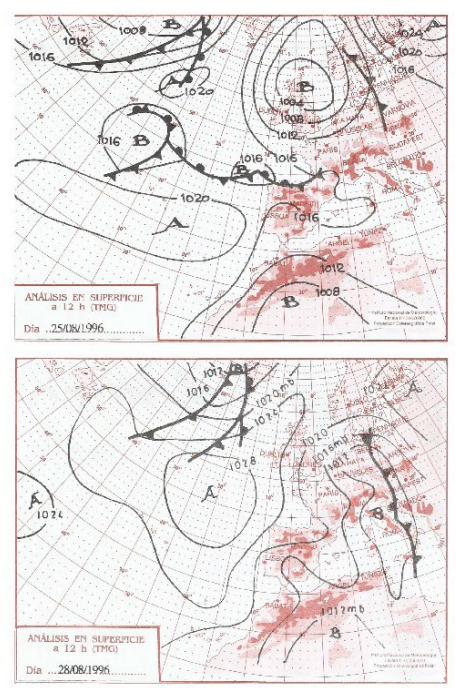

A) Evolución del comportamiento del oleaje y nivel de marea; B) Configuración atmosférica en superficie los días 25 y 28; C) Valores del oleaje, viento y mareas

Fuente: Puertos del Estado y [AEMET]. Elaboración propia.

\section{Conclusiones}

Intervenir en el territorio requiere de un conocimiento adecuado de su estructura y funcionamiento; hecho necesario cuando, además, implica actuaciones que pueden comprometer no solo su viabilidad, sino también la del grupo humano que lo ocupa o acude a él para el desarrollo de sus actividades. Estas circunstancias concurren en San Andrés por su condición de núcleo de población y ámbito hacia el que la ciudad de Santa Cruz de Tenerife ha canalizado, en cierta medida, una parte de su desarrollo.

La utilización del frente costero de San Andrés es una constante a lo largo de su existencia, por lo que su transformación, a demanda de la del núcleo capitalino, ha supuesto la aparición de situaciones de riesgo ligadas a episodios de temporal marino y de inundación por rebase del mar. Todo ello en un ámbito cuyo oleaje medio anual se define por su moderación, fruto del abrigo que ofrece la península de Anaga ante olas enérgicas que, desde el Atlántico Norte, arriban a la costa septentrional de Tenerife. Sin 
embargo, tal moderación es relativa, pues, aunque San Andrés se localiza en la vertiente este-sureste de la isla, no participa plenamente de las características propias de su oleaje. Lo demuestran parámetros tan representativos como la Hs y el $\mathrm{Tp}$, ya que superan los valores que se registran en ella de modo habitual, al no ser desconocidos los oleajes de swell, aun cuando predomine el sea a lo largo del año.

La identificación y caracterización de situaciones tormentosas y sobrepaso de las olas revisten interés de cara a la ordenación de los usos del suelo de esta localidad y de su entorno, desde el momento en que el dinamismo socioeconómico se vincula al frente costero. La alteración de la vida cotidiana se debe, sobre todo, a los temporales marinos, frecuentes y de marcada estacionalidad: en el primer caso, porque se producen casi dos por año y, en el segundo, por ser notable su estacionalidad, dado que la mayoría se concentran en invierno $(57,1 \%)$, siendo, por lo general, episodios de swell del N $(32,1 \%)$ y NNE $(30,4 \%)$, de unos dos días de duración en los que la Hs es de casi 3 metros. Estos rasgos difieren de los que concurren en las inundaciones, al ser fenómenos que se producen de modo preferente en verano; hecho al que se suma un desarrollo puntual en el tiempo y un origen que remite a las mareas vivas equinocciales, pues en estas circunstancias la altura de la Hs se mantiene dentro de lo habitual.

La aplicabilidad del análisis efectuado adquiere aún más sentido, si se tiene en cuenta que, en San Andrés, ha sido necesario adoptar costosas medidas estructurales que mitiguen los efectos de fenómenos adversos de origen natural como los considerados. Es el caso de los desperfectos que el fuerte oleaje causa en la Avenida Marítima, así como su cierre recurrente al tráfico rodado como medida de precaución. Siendo la principal vía de acceso al núcleo de población, ello comporta el cese de la actividad de los principales bares y restaurantes de la zona por la escasez de clientela y/o por inundación de los locales. Las pérdidas económicas consiguientes no son despreciables, máxime cuando coincide con la temporada alta de afluencia y fin de semana.

Figura 6. A) Defensa costera de la Playa de Las Teresitas y nuevo dique semisumergido de San Andrés. B) Perspectiva del dique desde la entrada a San Andrés
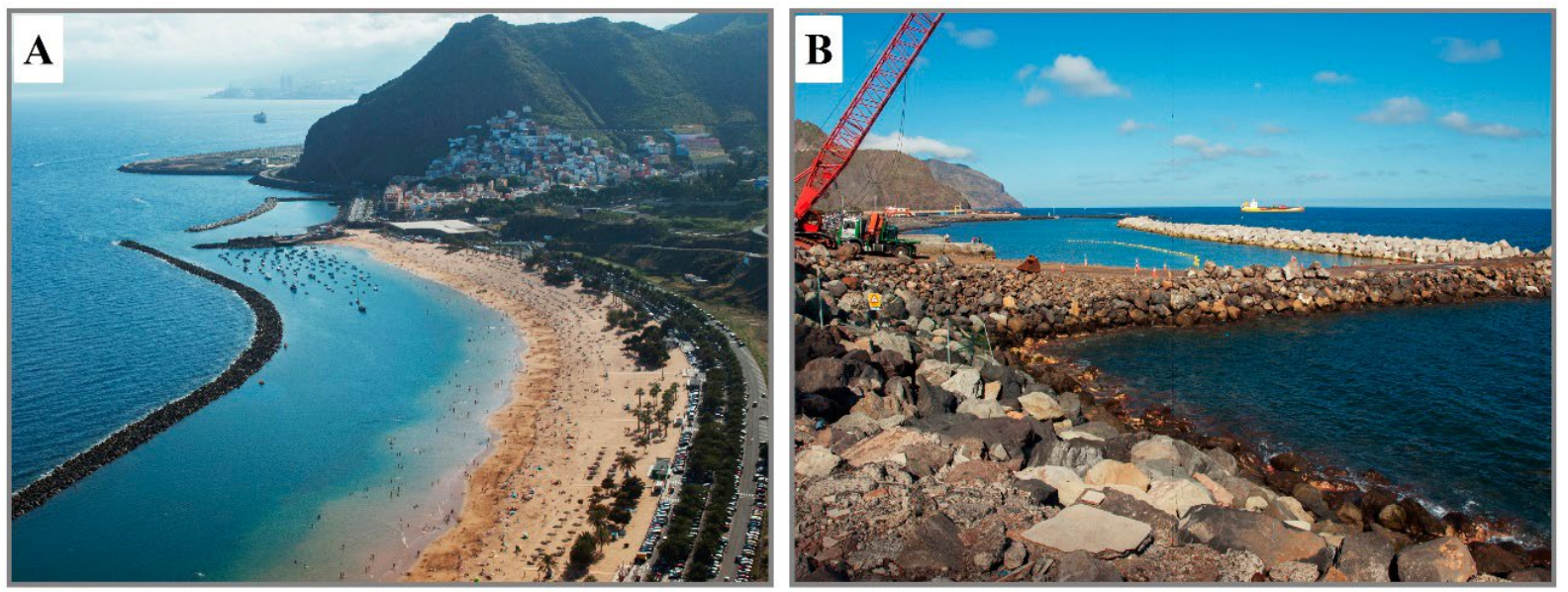

Fotografías de Rodríguez J.A. (abril, 2016)

No menos importante es la incertidumbre de los residentes ante la posibilidad de que el oleaje sea tan enérgico que inunde sus viviendas. Su petición de construcción de una nueva defensa costera es reiterada, sobre todo tras el episodio de agosto de 2011. La reclamación al Estado por parte de los vecinos de San Andrés y del Ayuntamiento de Santa Cruz de Tenerife, para que solucione los problemas de la escollera, se traduce en la realización de una nueva obra de protección. Con un coste de 3.157.723 euros y un plazo de ejecución de 10 meses, en junio de 2015 comienza la edificación de un dique de 350 metros de longitud a la cota +4 , con una distancia mínima desde la Avenida Marítima de 90 metros y una máxima desde la desembocadura del barranco del Cercado de 130 metros, además de un contradique de 60 metros de longitud (Puertos de Tenerife, 2015; La Opinión de Tenerife, 2016) (fig. 6). Estos trabajos terminan en mayo de 2016 (El Día, 2016).

La protección que propicia esta obra es evidente en relación con la aminoración de los efectos de la hidrodinámica litoral, pues desde su conclusión la Avenida Marítima no ha registrado alteración que impida su correcto funcionamiento. A pesar de que el lapso de tiempo analizado en este artículo finaliza 
en 2014, la consulta de datos horarios de Hs del modelo SIMAR 4028015, correspondientes a las medias mensuales de 2015 y 2016, respalda la efectividad del dique en relación con la disipación de la energía de la ola incidente y fricción contra el fondo. Dichos datos señalan que el proceder del oleaje extremal sigue las pautas reseñadas. La Hs registra valores máximos entre 3 y 4,8 metros de altura en algunos momentos muy puntuales de febrero y marzo de 2015 y entre 3 y 4 metros en febrero, marzo, octubre y diciembre de 2016; incluso en el episodio más reciente, el 2/11I/2017 la altura de la Hs llegó a alcanzar los 3,5 metros, mientras afecta también a toda la vertiente norte de Tenerife. Sin embargo, la prensa no se hace eco de la mayoría de ellos, dada la escasa o nula significación de sus secuelas. En el mejor de los casos se limita a consignar la alteración que introduce el oleaje durante la construcción del dique, como ocurre el 28/ IV/2016 cuando olas del S-SE de 2 metros de altura y 16-20 segundos de Tp generan una pequeña afección en el morro de la defensa costera en la que aún no se había dispuesto la totalidad de los bloques de hormigón (Diario de Avisos). Comentario similar concita el fuerte oleaje que se deja sentir en San Andrés el 20/X/2015, donde el agua no llega a la Avenida Marítima aun cuando las olas se llevan 60 metros de la escollera (La Opinión de Tenerife). En cualquier caso, lo cierto es que los temporales marinos puede que ya no revistan el mismo peligro, aunque el tiempo transcurrido es aún escaso para asegurar que han dejado de ser un fenómeno natural extraordinario y habrá que esperar a episodios similares a los extremos recogidos en este trabajo para comprobar realmente la eficacia de la infraestructura construida.

Por último, el estudio de las inundaciones costeras en Canarias es aún un tema por desarrollar. Su importancia es notable considerando las previsiones señaladas por el [IPCC] de un incremento del nivel medio del mar y la preocupación ante el aumento de fenómenos meteorológicos adversos. En un contexto insular donde la mayoría de la población y de las principales actividades económicas se localiza en la costa, es necesario evaluar los riesgos asociados al mar, de modo que la planificación territorial del frente costero tenga carácter integral. Este trabajo, con una vertiente local, trata de ser uno de los primeros que aborde una temática que aúna vulnerabilidad, amenaza marina y calentamiento global en el archipiélago canario.

\section{Referencias}

Afonso, J. A. (2007). El clima marítimo de Canarias, oleajes temporales y su predicción. Boletín de la Real Sociedad Económica de Amigos del País de Tenerife, 261-312.

Afonso, J. A. (2011). Canarias y los eventos extremos en el mar. Boletín de la Real Sociedad Económica de Amigos del País de Tenerife, 2010, 63-114.

Agencia Estatal de Meteorología [AEMET]. Recuperado de http://www.aemet.es/es/portada

Banco de Datos Oceanográfico de Puertos del Estado. Recuperado de http://www.puertos.es/es-es

Benavente, J., Bello, E., Anfuso, G., Nachite, D. y Macías, A. (2007). Sobreelevación debida a temporales y cambios producidos en las playas del litoral NE marroquí. Rev. CEG, 21 (1-1), 13-25.

Benavente, J., del Río, L. y Gracia, F. J. (2009). Riesgos litorales. Enseñanza de las Ciencias de la Tierra, 17(3), 277-283.

Bethencourt, J. \& Dorta, P. (2010). The storm of November 1826 in the Canary Islands: possibly a tropical cyclone? Geografiska Annaler, 92 A (3), 329-337. http://dx.doi.org/10.1111/j.1468-0459.2010.00398.x

Biblioteca Digital de la Universidad de La Laguna. Prensa extraída de los diarios Canarias 7, Diario de Avisos, El Día, Jornada Deportiva, La Gaceta, La Opinión de Tenerife y La Provincia. Recuperado de https://www.ull.es/view/institucional/bbtk/Prensa_canaria_digitalizada/es

Cabildo Insular de Tenerife. Servicio Técnico de Conservación, Explotación de Carreteras y Paisaje. (2015). Intensidades de tráfico en las carreteras de la isla de Tenerife en el año 2014. Recuperado de http://www.tenerife.es/portalcabtfe/images/PDF/temas/carreteras/resumen_2014.pdf

Cartográfica de Canarias S.A. [GRAFCAN]. Recuperado de https://www.grafcan.es/

Consejo Insular de Aguas de El Hierro. (s.f.). Consejo Insular de Aguas de El Hierro. Recuperado de http:// www.aguaselhierro.org/planificacion/inundaciones

Consejo Insular de Aguas de Tenerife. (2014). Mapas de peligrosidad y riesgo de inundación de las ARPSIs costeras en la Demarcación Hidrográfica de Tenerife. Recuperado de http://www.aguastenerife.org/17 RiesgoInundacionesTF/pdf/MapasCosteros/INTRODUCCION.pdf 
Cordobés, J. (2014). Caracterización hidráulica del paseo marítimo de San Andrés, Tenerife. Escuela Técnica Superior de Ingeniería Civil e Industrial. Universidad de La Laguna. Recuperado de http://riull. ull.es/xmlui/handle/915/294

Criado, C. \& Dorta, P. (2003). An unusual blood rain over Canary Island (Spain). The storm of January 1999. Journal of Arid Environments, 55, 765-783. https://doi.org/10.1016/S0140-1963(02)00320-8

Diario de Avisos (10 de septiembre de 2011). San Andrés, lo que es más urgente hacer. Diario de Avisos. Recuperado de http://www.diariodeavisos.com/2011/09/san-andres-lo-que-es-mas-urgente-hacer/

Diario de Avisos (11 de mayo de 2012). El Ayuntamiento desviará dinero de otras obras hacia San Andrés. Diario de Avisos. Recuperado de http://www.diariodeavisos.com/2012/05/el-ayuntamiento-desviaradinero-de-otras-obras-hacia-san-andres/

Diario de Avisos (8 de enero de 2014). Un poderoso mar de fondo castiga la costa del norte de Tenerife. Diario de Avisos. Recuperado de http://www.diariodeavisos.com/2014/01/poderoso-mar-fondocastiga-costa-del-norte-tenerife/

Directiva 2007/60/CE del Consejo, 23 de octubre de 2007, relativa a la evaluación y gestión de los riesgos de inundación. Diario Oficial de la Unión Europea, 6 de noviembre de 2007, núm 288, pp. 27-34. Recuperado de https://www.boe.es/buscar/doc.php?id=DOUE-L-2007-82010

Duce, E. (1995). Riesgos climáticos y la prensa: los efectos de los fenómenos meteorológicos sobre la agricultura en España; en el diario La Vanguardia, entre 1985 y 1990. Situaciones de riesgo climático, 223-232.

El Día (8 de enero de 2014). El oleaje causa daños en Puerto de la Cruz, Tacoronte y Garachico. El Día. Recuperado de http://web.eldia.es/norte/2014-01-08/5-oleaje-causa-danos-Puerto-Cruz-TacoronteGarachico.htm

El Día (17 de mayo de 2016). Concluye la construcción del dique de San Andrés. El Día. Recuperado de http://web.eldia.es/tenerife/2016-05-17/2-Concluye-construccion-dique-San-Andres.htm

Fraile, P., Sánchez, E., Fernández, M., Pita, Ma . F. y López, J. M. (2014). Estimación del comportamiento futuro del nivel del mar en las Islas Canarias a partir del análisis de registros recientes. Geographicalia (66), 79-98.

Grupo Intergubernamental de Expertos sobre el Cambio Climático [IPCC] (2013). Resumen técnico. En: Cambio climático 2013. Bases físicas. Contribución del Grupo de trabajo I al Quinto Informe de Evaluación del Grupo Intergubernamental de Expertos sobre el Cambio Climático. Cambridge University Press, Cambridge y Nueva York. Recuperado de http://www.ipcc.ch/home_languages_ main_spanish.shtml

Jordán, M. M., Boix, A., De la Fuente, C. y Sanfeliu, T. (1996). Dinámica de los arenales costeros en el caso de una playa regenerada. Las Teresitas (Tenerife). Geogaceta (19), 105-108. Recuperado de http:// www.sociedadgeologica.es/archivos/geogacetas/Geo19/Art29.pdf

La Opinión de Tenerife (19 de mayo de 2016). Concluye la obra del dique semisumergido de San Andrés. La Opinión de Tenerife. Recuperado de http://www.laopinion.es/tenerife/2016/05/19/autoridadportuaria-concluye-obra-dique/676212.html

Lionello, P. (s.f.). Extreme Sea Levels and Waves.

Máyer, P. (1999). Un siglo de temporales en la prensa de Gran Canaria. Vegueta, 4, 267-282. Recuperado de http://revistavegueta.ulpgc.es/ojs/index.php/revistavegueta/article/view/178

Medina, R. y Méndez, F. J. (2006). Inundación costera originada por la dinámica marina. Revista del Colegio de Ingenieros de Caminos, Canales y Puertos (74), 68-75.

Ministerio de Agricultura y Pesca, Alimentación y Medio Ambiente (2004). Impactos en la costa española por efecto del cambio climático. Fase III: Estrategias frente al cambio climático en la costa. Santander: Centro de Publicaciones del Ministerio.

Mora, J. I., Díaz-Hernandez, G., Medina, R., Maza, M., Lara, J. L., Dobos, D. y Rodríguez, B. (2013). Caracterización numérica de los eventos extremos de rebase e inundación y diseño de la protección costera en San Andrés, Tenerife. XII Jornadas Españolas de Ingeniería de Costas y Puertos.

Olcina, J. (2008). Cambios en la consideracion territorial, conceptual y de método de los riesgos naturales. Scripta Nova. Revista Electrónica de Geografía y Ciencias Sociales, XII(270 (24)), s.p. 
Olcina, J. (2011). Un mundo de riesgo. LYCHNOS(4): s.p. Recuperado de http://www.fgcsic.es/lychnos/ es_ES/articulos/un_mundo_de_riesgo

Pardo, J. (1991). La erosión antrópica en el litoral valenciano. Valencia, Consejería de Obras Públicas, Urbanismo y Transportes de la Generalitat Valenciana, $240 \mathrm{pp}$.

Pérez-Chacón, E., Hernández Calvento, L. y Yanes, A. (2007). Transformaciones humanas y sus consecuencias sobre los litorales de las Islas Canarias. En Etienne, S. y Paris, R (Ed.). Les littoraux volcaniques-Une approche environnementale. Estrasburgo: P.B.P.: 173-191.

Protección Civil del Ayuntamiento de Santa Cruz de Tenerife.

Puertos de Tenerife (2015). Arranca el dique de protección de 350 metros en el frente litoral de San Andrés. Recuperado de http://www.puertosdetenerife.org/index.php/es/noticias/2009-arranca-eldique-de-proteccion-de-350-metros-en-el-frente-litoral-de-san-andres

Puertos del Estado. (2015a). Conjunto de datos SIMAR. Recuperado de http://calipso.puertos.es/BD/ informes/INT_8.pdf

Puertos del Estado. (2015b). Conjunto de datos REDMAR. Recuperado de http://calipso.puertos.es/BD/ informes/INT_3.pdf

Puertos del Estado. (s.f.). Extremos máximos de oleaje (altura significante). Boya de Tenerife. Recuperado de http://calipso.puertos.es/BD/informes/EXT_BO_2446.pdf

Rangel, N. \& Anfuso, G. (2013). Winter Wave Climate, Storms And Regional Cycles: The SW Spanish Atlantic Coast. International Journal of Climatology, 2142-2156. http://dx.doi.org/10.1002/joc.3579

Rangel, N. y Anfuso, G. (2014). Temporales marítimos en el Atlántico español: clasificación, tendencias e impactos. En Botero, C. M., Monserrat A. L. y Pereira C.I.: Radiografía de la costa. Múltiples miradas científicas de los sistemas socio-naturales costeros de Iberoamérica y el Norte de África, 37-53.

Real Decreto-Ley 903/2010, de 9 de julio, de evaluación y gestión de riesgos de inundación. Boletín Oficial del Estado, 15 de julio de 2010, núm. 171, 61954-61967. Recuperado de https://www.boe.es/ diario boe/txt.php?id=BOE-A-2010-11184

Sabaté, F. (2012). Recuerdos del futuro: la experiencia vernácula y la sostenibilidad. En Afonso-Carrillo, J. (Ed.): Agricultura en Canarias: conciliando tradición y ciencia. Puerto de la Cruz (Tenerife), Actas VII Semana Científica Telesforo Bravo. Instituto de Estudios Hispánicos de Canarias 105-144.

Seisdedos, J., Mulas, J., González de Vallejo, L. I., Rodríguez Franco, J. A., Gracia, F. J., Del Río, L. y Garrote, J. (2013). Estudio y cartografía de los peligros naturales costeros de la región de Murcia. Boletín Geológico y Minero, 124(3), 505-520.

Tros de Ilarduya, M. (2005). Temporales marítimos y ordenación del territorio en la provincia de Alicante. Boletín de la A.G.E.(40), 329-350.

Tros de Ilarduya, M. (2012). Áreas de riesgo frente a temporal de mar en la provincia de Alicante. Anales de Geografía, 181-196. https://doi.org/10.5209/rev_AGUC.2012.v32.n1.39313

Yanes, A. y Marzol, M. V. (2009). Los temporales marinos como episodios de riesgo en Tenerife a través de la prensa (1985-2003). Revista de la Sociedad Geológica de España, 22(1-2), 95-104. Recuperado de http://www.sociedadgeologica.es/archivos/REV/22(1-2)/art08.pdf

Yanes, A., Marzol, V. y Romero, C. (2007). Temporales marinos en Tenerife: propuesta tipológica. Palma de Mallorca, IV Jornadas Nacionales de Geomorfología Litoral, 147-151. 